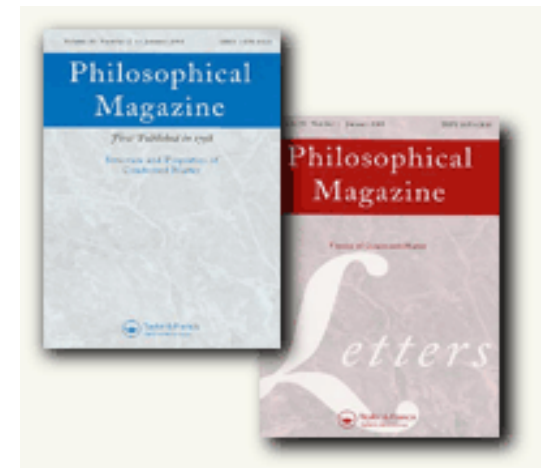

\title{
Computer simulation of reactions between an edge dislocation and glissile self-interstitial clusters in iron
}

\begin{tabular}{|c|c|}
\hline Journal: & Philosophical Magazine \& Philosophical Magazine Letters \\
\hline Manuscript ID: & TPHM-05-Oct-0441.R1 \\
\hline Journal Selection: & Philosophical Magazine \\
\hline $\begin{array}{r}\text { Date Submitted by the } \\
\text { Author: }\end{array}$ & 22-Dec-2005 \\
\hline Complete List of Authors: & $\begin{array}{l}\text { Bacon, David; University of Liverpool, Engineering } \\
\text { Osetsky, Yuri; Oak Ridge National Laboratory, Computer Science } \\
\text { and Mathematics Division } \\
\text { Rong, Zhouwen; University of Liverpool, Engineering }\end{array}$ \\
\hline Keywords: & $\begin{array}{l}\text { radiation damage, computer simulation, dislocation dynamics, } \\
\text { plasticity of metals, point defects }\end{array}$ \\
\hline Keywords (user supplied): & dislocation loop, iron, interstitial cluster \\
\hline
\end{tabular}

\section{S) ScholaroNE}


Computer simulation of reactions between an edge dislocation and glissile self-interstitial clusters in iron

\author{
D.J. Bacon' ${ }^{1}$, Yu.N. Osetsky ${ }^{2}$ and Z.Rong ${ }^{1}$
}

1) Materials Science and Engineering, Department of Engineering, The University of Liverpool, Liverpool L69 3GH, UK.

2) Computer Science and Mathematics Division, Oak Ridge National Laboratory, P. O. Box 2008, Oak Ridge, TN 37831-6158, USA.

\begin{abstract}
Clusters of self-interstitial atoms (SIAs) are formed in metals by high-energy displacement cascades, often in the form of small dislocation loops with a perfect Burgers vector, $\boldsymbol{b}$. Atomic-scale computer simulation is used here to investigate their reaction with an edge dislocation gliding in $\alpha$-iron under stress for the situation where $\boldsymbol{b}$ is inclined to the dislocation slip plane. $\boldsymbol{b}$ of small loops (37 SIAs here) changes spontaneously and the interstitials are absorbed as a pair of superjogs. The line glides forward at critical stress $\tau_{c}$ when one or more vacancies are created and the jogs adopt a glissile form. A large loop (331 SIAs here) reacts spontaneously with the dislocation to form a segment with $\boldsymbol{b}=$ $<100>$, which is sessile on the dislocation slip plane, and as applied stress increases the dislocation side arms are pulled into screw orientation. At low temperature $(100 \mathrm{~K})$, the $<100>$ segment remains sessile and the dislocation eventually breaks free when the screw dipole arms cross-slip and annihilate. At $300 \mathrm{~K}$ and above, the segment can glide across the loop and transform it into a pair of superjogs, which become glissile at $\tau_{\mathrm{c}}$. Small loops are weaker obstacles than voids with a similar number of vacancies, large loops are stronger. Irrespective of size, the interaction processes leading to superjogs are efficient for absorption of SIA clusters from slip bands, an effect observed in flow localisation.
\end{abstract}

Corresponding author: D.J. Bacon (djbacon@liv.ac.uk)

Keywords: Computer simulation, dislocation loop, interstitial cluster, iron, radiation damage 


\section{Introduction}

Exposure of metals to fast-neutron irradiation can cause a substantial increase in yield stress and a reduction in ductility due to the interaction of dislocations with obstacles on or near their slip plane. The obstacles are formed largely by point defect clusters created in displacement cascades. Molecular dynamics (MD) computer simulations have shown that the self-interstitial atom (SIA) component of primary radiation damage is mainly in the form of platelets of closely-packed, parallel crowdions that are equivalent to small, nanometre-scale interstitial dislocation loops with perfect Burgers vector, $\boldsymbol{b}$, parallel to the crowdion axis, e.g. [1,2]. Atomistic simulations of a variety of BCC, FCC and HCP metals have shown that such loops are glissile and move in one dimension parallel to the crowdion axis by thermally-activated events with a low activation energy of $\sim 0.02 \mathrm{eV}$ [35]. They have a long-range strain field and can interact with dislocations by either intersecting their slip plane or gliding to decorate them in regions where they are attracted by the dislocation stress field. The latter possibility has support from experiment, e.g. [6], and modelling, e.g. [7,8]. Further, the interaction of gliding dislocations with loops clearly influences the flow stress and ductility of irradiated metals, and is believed to play an important role in flow localisation and the formation of slip channels that appear to be cleared of radiation damage debris [9].

Decoration of dislocation sources by 'atmospheres' of interstitial loops led Singh and co-workers [10] to argue that the increase in the upper yield stress and the subsequent yield drop are related to the stress necessary to unlock dislocations from the loops that decorate them. Estimates of the unlocking stress for a straight dislocation were found to be consistent with experiment. A continuum dislocation dynamics method was later used to determine the stress for a flexible dislocation to break away from rows of loops below the slip plane and confirmed the earlier estimates [11,12]. These treatments assumed the interstitial loops to be static and unable to glide with a dislocation, whereas perfect loops are intrinsically glissile and those nearest the slip plane not only exert the largest force on the dislocation but also experience the largest force tending to make them glide. This was pointed out by Makin [13], who calculated the long-range elastic interaction between a dislocation and loop and noted that loops lying close to the glide plane of a dislocation 
with the same $\boldsymbol{b}$ may be swept along with it, although the effect could not be quantified in the absence of information on the force to move a loop at the atomic scale.

The present work is part of a series of atomic-scale studies of the dynamics of dislocation behaviour in the presence of interstitial loops in $\alpha$-iron $(\mathrm{Fe})$. Loops with $\boldsymbol{b}=$ $1 / 2<111>$ and $<100>$ grow during irradiation of this metal. The origin of the latter, which have the larger elastic energy, is unclear. It has been proposed that both sets could result by shear from a common $1 / 2<110>$ nucleus [14], or that two intersecting $1 / 2<111>$ clusters can react to form a $<100>$ loop [15]. However, neither mechanism has yet been demonstrated to occur and the $1 / 2<111>$ configuration has lower energy than $<100>$ using all currently available interatomic potentials. Since $1 / 2<111>$ SIA clusters arise in irradiated iron and other BCC metals, we have concentrated on them in the first part of this study. In any case, it is not obvious a priori which creates the stronger obstacle to glide of a dislocation with $\boldsymbol{b}=1 / 2<111>$ because the dislocation can react favourably with a $1 / 2<111>$ loop to form a $<100>$ segment, which can be sessile (see later), whereas the favourable reaction with a $<100>$ loop results in another $1 / 2<111>$ segment, which is glissile. Thus, both loop types need to be studied and we will report on treatment of $<100>$ loops in a second part.

Previously, the interaction of a $1 / 2<111>\{110\}$ edge dislocation gliding under applied stress with sets of $1 / 2<111>$ SIA clusters of size $\sim 1 \mathrm{~nm}$ distributed below the extra half-plane was simulated for a range of temperature [16,17]. It was found that a row of loops can be dragged at almost the free-flight velocity of the dislocation $\left(\sim 100 \mathrm{~ms}^{-1}\right.$ for $10 \mathrm{MPa}$ at $300 \mathrm{~K})$. A quantitative model for this, based on a drag coefficient derived from the diffusivity of interstitial loops, was presented, and the conditions under which a dislocation breaks away from a row of glissile loops was determined. Perfect dislocation loops in this metal have $\boldsymbol{b}$ equal to one of the four possible vectors $1 / 2<111>$, but only two of them are parallel to the $\{110\}$ slip plane of a dislocation and were considered for drag. Glissile loops with one of the other two $\boldsymbol{b}$ s can move to intersect the dislocation glide plane, however, and cause direct dislocation-dislocation reaction. This latter process is modelled in the present work and its dependence on temperature, $\mathrm{T}$, applied shear strain rate, $\dot{\varepsilon}$, and loop size analysed. We have again considered the edge dislocation.

Although it is well known that glide of screw dislocations controls slip in BCC metals at low $\mathrm{T}$, it should be noted that edge dislocations have to interact/absorb/overcome loops for plastic flow to occur at any temperature. Their mechanisms therefore have to be 
investigated since there is no reason to suppose a priori that they are not important. Furthermore, dislocation glide can result in the production of cleared channels, as noted above, and, although some static and dynamic simulations of screw- $1 / 2<111>$ loop interaction have been reported [18,19], we are not aware of evidence that screw dislocations absorb/remove loops to result in clear band formation.

The method employed here is summarised in section 2 and the results presented in section 3. Section 4 contains a discussion of the investigation, including an assessment of its consequences for understanding the effects of irradiation on plasticity in iron. We also compare the present results with those of a very recent MD simulation of dislocation-loop interaction in iron with the same geometry as used here by Nomoto et al. [20] and with a qualitatively similar study of dislocation-loop interaction in the FCC metal nickel by Rodney and Martin [21,22].

\section{Method and geometry}

The method developed by Osetsky and Bacon [23], which treats a periodic array of edge dislocations, was employed. The $\mathrm{x}, \mathrm{y}$ and $\mathrm{z}$ axes of the simulated crystal were oriented along [111], [ $\overline{1} \overline{1} 2]$ and $[1 \overline{1} 0]$ directions, as illustrated in Fig. 1. Periodic boundary conditions were employed in the $\mathrm{x}$ and $\mathrm{y}$ directions, corresponding to the direction of $\boldsymbol{b}$ and the line direction, respectively, and fixed conditions were used across the $\mathrm{z}$ boundaries. Choice of crystal dimensions is important for modelling dislocation motion because the size, $L_{x}$, along the $x$-axis should be large enough for interactions between the dislocation and its images to be insignificant [23]. We used $L_{x}=120 b(\sim 29.8 \mathrm{~nm}$ for Fe with model lattice parameter $\mathrm{a}_{0}=0.2867 \mathrm{~nm}$ at temperature $\mathrm{T}=0 \mathrm{~K}$ ); the period, $\mathrm{L}_{\mathrm{y}}$, defines the inter-cluster spacing and was $59 \sqrt{ } 6 \mathrm{a}_{0}(\sim 41.4 \mathrm{~nm})$; and $\mathrm{L}_{\mathrm{z}}$ was $49 \sqrt{2} \mathrm{a}_{0}(\sim 19.9 \mathrm{~nm})$. The total number of mobile atoms in the MD cell was $\sim 2.1 \mathrm{M}$.

Rigid blocks of atoms were used at the z-axis boundaries to apply shear strain, $\varepsilon$, by displacement of the $+\mathrm{z}$ block. The corresponding applied shear stress, $\tau\left(=\tau_{\mathrm{xz}}\right)$, was computed from the shear force on this block due to the free atoms of the inner region (see [23]). Molecular statics (MS) relaxation, i.e. potential energy minimisation, was used to simulate athermal loading at $\mathrm{T}=0 \mathrm{~K}$ under strain increasing in increments $\Delta \varepsilon=2$ to $10 \times 10^{-}$ 5. Molecular dynamics (MD) with timestep 2-5fs was used for constant-strain-rate 


\section{Results}

\subsection{Reaction at $T=0 \mathrm{~K}$}

Under the attractive field of the dislocation, and even in the absence of thermal motion of the atoms, small SIA loops glide over the $\mathrm{H}$ range considered to meet the dislocation as it moves under strain on its slip plane. (The thickness of cleared channels was not a concern of this work, but the band of interaction over which loops can glide to an edge dislocation must at least $33 \mathrm{a}_{0}$, even at $\mathrm{T}=0 \mathrm{~K}$. It was not feasible to model larger crystals to investigate this dimension further.) The dislocation actually bows forward as a loop approaches in order to assist the favourable reaction. Fig. 2(a) shows a visualisation of the initial dislocation line and 37-SIA cluster viewed from the front of the model crystal in Fig. 1. The dislocation has already started to bow forward slightly and as it moves further under the applied strain the loop slips on its glide cylinder along [1 $\overline{1} 1]$ to meet it. The axis of the crowdions then changes to [111], i.e. $\boldsymbol{b}$ of the SIA loop rotates to be the same as that of the dislocation line. The newly-formed pair of superjogs restricts the slip of the dislocation (Fig. 2(b)) until the SIAs that form it reorganise by self-climb and emission of a vacancy in the crystal to give glissile segments on $\{110\}$ or $\{112\}$ planes of 
the [111] zone axis, as seen in Fig. 2(c). The jogged dislocation then continues to glide with little hindrance.

The relationship between $\tau$ and $\varepsilon$ during the process is plotted in Fig. 3. In the absence of any other defect, the edge dislocation glides on a $\{110\}$ plane in the model at $\mathrm{T}$ $=0 \mathrm{~K}$ under applied resolved shear stress of about $25 \mathrm{MPa}[23]$ : this is the Peierls stress, $\tau_{\mathrm{P}}$. As the dislocation approaches the periodic row of SIA clusters, it is initially attracted towards them $\left(\tau<\tau_{\mathrm{P}}\right)$ and becomes pinned by the double superjogs formed by the reaction. $\tau$ rises as $\varepsilon$ increases until reaching a maximum (i.e. critical) stress $\tau_{c}=51 \mathrm{MPa}$, at which stage a vacancy is created and the superjogs become glissile on the $\boldsymbol{b}=1 / 2[111]$ system and $\tau$ falls to $\tau_{\mathrm{P}}$. The process described does not depend on the increment $\Delta \varepsilon$ used here, as seen from the two sets of data in Fig. 3.

The simulations for $\mathrm{T}=0 \mathrm{~K}$ provide information on the equilibrium (minimum potential energy) structure at each strain increment, and the configurations are equivalent to those that would be obtained by minimising the elastic energy in the continuum approximation. However, they do not necessarily reveal information about the atomic mechanisms that would occur in a real metal where thermal effects assist the reaction process. For this reason, most modelling has been done using MD, as described in the following section.

\subsection{Reaction at $T>0 K$}

\subsubsection{Small loops}

The aim of this part of the study was to examine the effect of cluster size, temperature and $\dot{\varepsilon}$ on the reaction and strengthening mechanism. The 37-SIA cluster is considered first. Its interaction with the edge dislocation has been investigated for $\mathrm{T}=$ 100,300 and $450 \mathrm{~K}$ in a model with applied $\dot{\varepsilon}$ values in the range $2-10 \times 10^{6} \mathrm{~s}^{-1}$. (For the dislocation density $\left(\mathrm{L}_{\mathrm{x}} \mathrm{L}_{\mathrm{z}}\right)^{-1}$ used here, this corresponds to dislocation velocity in steady state of $5-24 \mathrm{~ms}^{-1}$.) Under all conditions considered, the cluster glides to meet the dislocation and the axis of its crowdions rotates from [1 111$]$ to [111] when the cores of the two defects react. This results in creation of a pair of superjogs, which hinders slip of the dislocation and results in increasing $\tau$ until the interstitials in the superjogs reorganise by emitting a vacancy and form glissile segments on slip planes of the [111] zone. The 


\subsubsection{Large loops}

Loops containing 37 SIAs are typical of those formed directly in the primary displacement cascade process, which is consistent with the mean size $\sim 1 \mathrm{~nm}$ observed experimentally at low irradiation dose $\left(\sim 10^{-3} \mathrm{dpa}\right)$ [25-27]. These loops are highly mobile and can move by mutual attraction to form larger dislocation loops, as seen in MD simulations [28] and, therefore, loop size increases with irradiation dose, reaching $\sim 5 \mathrm{~nm}$ at $\sim 1 \mathrm{dpa}$ [25-27]. Thus, we now consider loops containing 331 interstitials; they have $\mathrm{d}=$ $2.46 \mathrm{~nm}$, which is equivalent to diameter $\sim 5 \mathrm{~nm}$.

Five frames showing the interaction at $300 \mathrm{~K}$ for $\dot{\varepsilon}=20 \times 10^{6} \mathrm{~s}^{-1}$ are presented in Fig. 5. Initially, the loop glides towards the dislocation glide plane and its upper segment attracts the dislocation, which bows forward (Fig. 5(a)). When they meet (Fig. 5(b)), the Burgers vector of the upper segment is transformed by the reaction

$$
1 / 2[111]+1 / 2[\overline{1} 1 \overline{1}]=[010],
$$

which is energetically-favourable according to Frank's rule. The remainder of the initial loop retains its $1 / 2[1 \overline{1} 1]$ Burgers vector. The [010] segment is sessile in the (1 $\overline{1} 0)$ slip 
plane of the dislocation, but glissile in the inclined (101) plane. However, it is pinned at its ends by the junctions with the $1 / 2[111]$ and $1 / 2[\overline{1} 1 \overline{1}]$ lines, and is too short to bow under the applied stress. As $\tau$ increases, the $1 / 2[111]$ line segments pinned at the junctions are pulled into the screw orientation (Fig. 5(c)) and, assisted by the applied force on the [010] segment, cross-slip on (10 $\overline{1})$ planes, thereby allowing the [010] segment to slip downwards on the (101) plane. This is shown in the view along $[\overline{1} \overline{1} \overline{1}]$ in Fig. 5(d). Eventually, at high enough applied stress, the downwards slip of the [010] dislocation and the [111] screw side arms completes the transformation of the loop into a pair of $1 / 2$ [111] superjogs on the gliding dislocation, wherein all 331 SIAs are contained (Fig. 5(e)). A few vacancies are formed in the crystal at the point when the dislocation glides forward at $\tau_{c}$, in a similar manner to the small loop above, resulting in additional SIAs in the jogs. The reaction and transformation is completed in less than $0.8 \mathrm{~ns}$ at this strain rate. It is shown in schematic representation in Fig. 6. The arrows denoting the direction of $\boldsymbol{b}$ are obtained using the RH/FS convention with the positive line sense indicated [29].

The maximum stress, $\tau_{\mathrm{c}}$, for the process in Fig. 5 is $220 \mathrm{MPa}$ and the jogged dislocation line continues to glide at $\tau=12 \mathrm{MPa}$. The same reaction and transformation process occurred for the other two $\dot{\varepsilon}$ at $300 \mathrm{~K}$ and at $450 \mathrm{~K}$. The value of $\tau_{\mathrm{c}}$ depends on $\mathrm{T}$ and $\dot{\varepsilon}$, however, as shown by the data plotted in Fig. 4. The interaction was also simulated for $\mathrm{T}=450 \mathrm{~K}$ and $\dot{\varepsilon}=5 \times 10^{6} \mathrm{~s}^{-1}$, but with the sense of the applied strain reversed, i.e. the dislocation approached the loop from the right-hand side of the model in the schematic illustration of Fig. 1. The critical stress was the same as that in Fig. 4 and the transformation and unpinning processes were unchanged.

The interaction at $100 \mathrm{~K}$ and $\dot{\varepsilon}=5 \times 10^{6} \mathrm{~s}^{-1}$ resulted in $\tau_{\mathrm{c}}=290 \mathrm{MPa}$ (see Fig. 4) and had a different outcome. Two frames in the process are shown in Fig. 7. Creation of a [010] segment by the reaction of eq. (1) occurred again (Fig. 7(a)), but the segment was seen to be sessile in the loop plane at this low temperature and a long screw dipole formed on the $1 / 2[111]$ dislocation under increasing stress (Fig. 7(b)). The dipole eventually annihilated by cross-slip of its arms, which has started in Fig. 7(b), and the $1 / 2[1 \overline{1} 1]$ loop was restored. Thus, both the strength of large loops and the ease with which they are absorbed as superjogs depend on temperature via the mobility of $<100>$ segments.

\section{Discussion}


This research shows clearly that the interaction mechanism between an edge dislocation and a $1 / 2<111>$ interstitial loop whose glide cylinder intersects the dislocation slip plane depends on the size of the loop. Consequently, the obstacle strength provided by a loop against dislocation motion depends on loop size and, for large loops, also changes with temperature and applied $\dot{\varepsilon}$. Small loops (37 SIAs here) offer the least resistance because, even in the absence of thermal effects $(T=0 \mathrm{~K})$, they are able to undergo rotation of the crowdion axis, $\boldsymbol{b}$, on meeting the dislocation and be absorbed on it as a double superjog. (A few simulations have been performed for 61-SIA loops, and the $\boldsymbol{b}$-rotation and loop absorption process is the same.) The maximum stress corresponds to the creation of point defects as the core of the jog segments reorganises to become glissile. The superjogs have only a small drag effect on the line after this in both statics and dynamics simulations.

This stress-assisted transformation occurs at $\tau_{\mathrm{c}}=51 \mathrm{MPa}$ at $0 \mathrm{~K}$ and between 13 and $27 \mathrm{MPa}$ at $\mathrm{T}>0 \mathrm{~K}$ when the inter-loop spacing, $\mathrm{L}_{\mathrm{y}}$, equals $41.4 \mathrm{~nm}$. This compares with $\tau_{\mathrm{c}} \sim$ 100 and $118 \mathrm{MPa}$ at $\mathrm{T}=0 \mathrm{~K}$ for an edge dislocation to cut through a row of spherical voids in iron containing a similar number (27 or 59 ) of vacancies and with the same spacing. Thus, small dislocation loops are relatively weak obstacles compared with voids. Note, however, that all the SIAs are absorbed by the line in the form of a double superjog: only a few vacancies are absorbed by climb when a dislocation passes through a void at $\mathrm{T}=0 \mathrm{~K}$ [30]. Furthermore, superjogs increase the interaction cross-section of a dislocation for reaction and/or annihilation with other defects in a crystal. Thus, the SIA-loop absorption process should be effective in assisting the creation of defect-free channels when slip occurs in irradiated iron.

This absorption effect for small loops is similar to that found in simulation of edge dislocation-SIA loop interaction in nickel by Rodney and Martin [21,22]. Loops with 4-37 interstitials and a $<110>$ crowdion axis were absorbed by the dislocation, which is dissociated in the FCC structure, by rotation of their axis (b). This resulted in either transformation into a pair of superjogs on the dislocation, as here, or attachment to one of the Shockley partials by means of a dislocation junction. Furthermore, recent simulations have shown that rotation of $\boldsymbol{b}$ also occurs for small clusters of crowdion SIAs gliding into contact with an edge dislocation of the prism-slip system in $\alpha$-zirconium [31]. This metal 
has the HCP crystal structure, and so the rotation-absorption process requiring relatively low stress seems quite general for loops with up to a few tens of defects. Note that rotation requires contact interaction with a dislocation: it does not occur for SIA clusters in isolation if they contain more than four or five interstitials [32].

The reaction with a large loop (331 SIAs here) provides a much stronger obstacle to dislocation motion than that with a small loop because spontaneous rotation of $\boldsymbol{b}$ when the two defects first meet does not occur. Instead, a segment with $\boldsymbol{b}=<100>$ is formed. It is sessile in the dislocation glide plane and can only glide across the loop plane and complete the transformation to $\boldsymbol{b}=1 / 2<111>$ when, under sufficiently high $\tau$, the dislocation side arms are pulled into screw orientation and then cross-slip (Fig. 6). $\tau_{\mathrm{c}}$ is not only much higher but also more strongly temperature-dependent for this process. In fact, glide of the $<100>$ segment does not occur at $100 \mathrm{~K}$, i.e. it is effectively immobile, and the high value of $\tau_{\mathrm{c}}$ is controlled by cross-slip and annihilation of the arms of the $1 / 2<111>$ screw dipole. In this case, the original loop is restored at dislocation breakaway, rather than absorbed.

Unlike the situation for small obstacles, $\tau_{\mathrm{c}}$ for 331-SIA loops is higher than for voids with a similar number of vacancies. For example, $\tau_{\mathrm{c}}$ equals $150 \mathrm{MPa}$ at $\dot{\varepsilon}=5 \times 10^{6} \mathrm{~s}^{-1}$ for spherical voids containing 339 vacancies in iron at $300 \mathrm{~K}$ with the same spacing as here [30], compared with $212 \mathrm{MPa}$ for 331 -SIA loops at $300 \mathrm{~K}$ and $290 \mathrm{MPa}$ at $100 \mathrm{~K}$, as shown by the $\tau$ versus $\varepsilon$ plots in Fig. 8 . Note that the edge dislocation shape at the critical stress $\tau_{\mathrm{c}}$ is similar to that in the Orowan mechanism, i.e. a dipole of two parallel screw segments with spacing close to the obstacle size. The effective size for the 331-SIA loop is larger than that for the 339-vacancy void, namely $\sim 5 \mathrm{~nm}$ compared with $\sim 2 \mathrm{~nm}$. This is probably the main reason for the higher $\tau_{\mathrm{c}}$ value for the 331-SIA loop because $\tau_{\mathrm{c}}$ for the Orowan configuration scales roughly as the logarithm of the obstacle size [33].

As with small loops, all the interstitials are absorbed in the pair of glissile superjogs, except at $100 \mathrm{~K}$, so the process can be expected to be efficient at removing damage from slip bands. We have not investigated the size, which may be T- and $\dot{\varepsilon}$ dependent, for the transition from small-to-large loop behaviour. Extensive modelling is required and will be the subject of a later paper.

Only one line length $\mathrm{L}_{\mathrm{y}}$ (= loop separation) is treated here, but results have general applicability for the following reasons. For large loops, where the dislocation side arms bend to the screw orientation, i.e. the line shape is that of the Orowan process (strong 
obstacles), the critical stress is found in continuum self-stress modelling [33] and MD/MS atomic-scale modelling of strengthening $[23,30,34]$ to be proportional to $\left(1 / \mathrm{L}_{\mathrm{y}}\right)$. For small loops that are absorbed by the dislocation, the stress is again proportional to $\left(1 / \mathrm{L}_{\mathrm{y}}\right)$ because the critical step (vacancy creation at the jog) is a localised process. Simple estimates of the stress $\tau_{c}$ required for the length $\mathrm{L}_{\mathrm{y}}$ to move forward and do work $\left(\approx \tau_{\mathrm{c}} \mathrm{b}^{2} \mathrm{~L}_{\mathrm{y}}\right)$ to create a vacancy confirm this.

In very recent work, Nomoto et al. [20] have reported MD simulation of the interaction of an edge dislocation with a periodic row of 99-SIA loops in iron with the same Burgers vector orientations as used here. The model size was only a little smaller than the one used here - $\mathrm{L}_{\mathrm{y}}$ was $35 \mathrm{~nm}$ compared with $41 \mathrm{~nm}$ - and the interatomic potential was the same. The temperature was not given in the paper. The final configuration found after the dislocation had reacted with the loop was the same as found here, viz. glissile superjogs and a few vacancies. However, the transformation mechanism described in [16] is different, for the $<100>$ dislocation ('bridge') formed initially was observed to split into two $1 / 2<111>$ segments that slipped down on the inclined $\{110\}$ plane. (For the orientation used here in Fig. 1, the equivalent process on the $(101)$ plane would be $[010]=1 / 2[11 \overline{1}]+$ $1 / 2[\overline{1} 11]$.) The difference may be due to the different loop size considered or, more likely, the way the crystal was loaded. The model in [20] was deformed by applying a constant shear stress rather than a constant strain rate. At $\tau=50 \mathrm{MPa}$, the dislocation was stopped by the loop and so stress in the range 150 to $650 \mathrm{MPa}$ was simulated for loop transformation and absorption. Under these high stress (and therefore high strain rate) conditions, the free-flight velocity of the edge dislocation is in excess of $1000 \mathrm{~ms}^{-1}[18,19]$, compared with $\sim 12 \mathrm{~ms}^{-1}$ at, say, $\dot{\varepsilon}=5 \times 10^{6} \mathrm{~s}^{-1}$ in the present work. Thus, the complete process took a few tens of ps in [20], compared with times one to two orders of magnitude longer for the much lower strain rates used here. The process simulated in [20] is strongly affected by kinetic effects such as observed elsewhere for high dislocation velocities $[34,35]$. Hence, it is not straightforward to compare the atomic mechanisms. Furthermore, critical stress values were not obtained by the procedure used in [20].

Finally, it should be emphasised again that, irrespective of the size of the interacting loop, complete absorption of the interstitials occurs by all but one of the interactions found here. In addition to removing damage from the crystal by this process, the superjogs on the gliding dislocation increase the possibility of dislocation interaction 
with other defects. This may enhance absorption of other SIAs or annihilation of vacancy defects. Investigation of this, and analysis of the drag effect such jogs have on slip, will be the subjects of a future paper.

\section{Conclusions}

(a) Perfect dislocation loops containing from a few tens to hundreds of self-interstitial atoms in iron lying within a few tens of $\mathrm{nm}$ of the slip plane of an edge dislocation can glide to react with the dislocation when the loop Burgers vector, $\boldsymbol{b}$, is inclined to the slip plane.

(b) The Burgers vector of small loops (37 SIAs here) changes spontaneously on contact and the interstitials are absorbed as a pair of superjogs. The line glides forward at critical stress $\tau_{\mathrm{c}}$ when one or more vacancies are created and the jogs adopt glissile form.

(c) $\tau_{\mathrm{c}}$ is $51 \mathrm{MPa}$ at $\mathrm{T}=0 \mathrm{~K}$ and lies between 13 and $27 \mathrm{MPa}$ for $100 \leq \mathrm{T} \leq 450 \mathrm{~K}$. These loops are weaker obstacles than voids with a similar number of vacancies.

(d) A large loop (331 SIAs here) reacts spontaneously with the dislocation to form a segment with $\boldsymbol{b}=\langle 100>$, which is sessile on the dislocation slip plane, and as $\tau$ increases the dislocation side arms are pulled into screw orientation. The $<100>$ segment is glissile on an inclined $\{110\}$ plane at 300 and $450 \mathrm{~K}$, and glides across the loop as the side arms cross-slip, thereby transforming the loop into a pair of superjogs, which, as in (b), becomes glissile at $\tau_{\mathrm{c}}$. The $<100>$ segment is immobile at $100 \mathrm{~K}$, however, and the dislocation breaks away from the loop by cross-slip and mutual annihilation of its screw side arms.

(e) $\tau_{\mathrm{c}}$ lies between 290 and $160 \mathrm{MPa}$ for $100 \leq \mathrm{T} \leq 450 \mathrm{~K}$. These loops are stronger obstacles than voids with a similar number of vacancies because of the larger effective size of loops.

(f) With the exception of the large loop at low temperature, the interaction process is efficient for absorption of SIA clusters from slip bands, as observed in flow localisation. 


\section{ACKNOWLEDGEMENTS}

This research was sponsored by (i) grant PERFECT (F160-CT-2003-508840) under programme EURATOM FP-6 of the European Commission, (ii) a research grant from the UK Engineering and Physical Sciences Research Council and (iii) the Division of Materials Sciences and Engineering and the Office of Fusion Energy Sciences, U.S. Department of Energy, under contract DE-AC05-00OR22725 with UT-Battelle, LLC. 


\section{References}

1. D.J. Bacon, F. Gao and Yu.N. Osetsky, J. Nucl. Mater. 2761 (2000).

2. Yu.N. Osetsky, D.J. Bacon, A. Serra, B.N. Singh and S.I. Golubov, Phil. Mag. A 83 61 (2003).

3. B.D. Wirth, G.R. Odette, D. Maroudas and G.E. Lucas, J. Nucl. Mater. 244185 (1997); ibid. 27633 (2000).

4. Yu.N. Osetsky, D.J. Bacon, A. Serra, B.N. Singh and S.I. Golubov, J. Nucl. Mater. 27665 (2000).

5. N. Soneda and T. Diaz de la Rubia, Phil. Mag. A 81 331(2001).

6. B.N. Singh, A. Horsewell, P. Toft, D.J. Edwards, J. Nucl. Mater. 224131 (1995).

7. Yu.N. Osetsky, D.J. Bacon, F. Gao, A. Serra and B.N. Singh, J. Nucl. Mater. 283-287 784 (2000).

8. $\quad$ N.M. Ghoniem, S. H. Tong, J. Huang, B.N. Singh and M. Wen, J. Nucl. Mater. 307311843 (2002).

9. M. Victoria, N. Baluc, C. Bailat, Y. Dai, M.I. Luppo, R. Schaublin and B.N. Singh, J. Nucl. Mater. 276114 (2000).

10. B.N. Singh, H. Trinkaus and A.J.E. Foreman, J. Nucl. Mater. 24991 (1997); ibid. 251, 172 (1997).

11. N.M. Ghoniem, S.H. Tong, B.N. Singh and L.Z. Sun, Phil. Mag. 812743 (2001).

12. Z. Rong, V. Mohles, D.J. Bacon and Yu.N. Osetsky, Phil. Mag. 85171 (2005).

13. M.J. Makin, Phil. Mag. 10695 (1964).

14. B.L. Eyre and R. Bullough, Phil. Mag. 1231 (1965).

15. J. Marian, B.D. Wirth and J.M. Perlado, Phys. Rev. Lett. 88 255507-1 (2002).

16. J. Marian, B.D. Wirth, R. Schäublin, G.R. Odette and J.M Perlado, J. Nucl. Mater. 323 181 (2003).

17. S. Jumel, J-C. Van Duysen, J Ruste and C. Domain, J. Nucl. Mater. 34679 (2005).

18. Yu.N. Osetsky, D.J. Bacon, Z. Rong and B.N. Singh, Phil. Mag. Lett. 84745 (2004).

19. Z. Rong, Yu.N. Osetsky and D.J. Bacon, Phil. Mag. 851473 (2005).

20. A. Nomoto, N. Soneda, A. Takahashi and S. Ishino, Mats. Trans. 46463 (2005).

21. D. Rodney and G. Martin, Phys. Rev. Lett. 823273 (1999).

22. D. Rodney and G. Martin, Phys. Rev. B 718714 (2000). 
23. Yu.N. Osetsky and D.J.Bacon, Modelling Simul. Mat. Sci. Eng. 11427 (2003).

24. G.J. Ackland, D.J. Bacon, A.F. Calder and T. Harry, Phil. Mag. A 75713 (1997).

25. B.N. Singh, A. Horsewell and P. Toft, J. Nucl. Mater. 271-272 77 (1999).

26. M.I. Luppo, C. Bailat, R. Schäublin and M. Victoria, J. Nucl. Mater. 283-287 483 (2000).

27. S.J. Zinkle and B.N. Singh, J. Nucl. Mater. (2005), in press.

28. Yu.N. Osetsky, A. Serra and V. Priego, J. Nucl. Mater. 276202 (2000).

29. D. Hull and D.J. Bacon, Introduction to Dislocations, $4^{\text {th }}$ edition, ButterworthHeinemann, 2001.

30. Yu.N. Osetsky and D.J. Bacon, J. Nucl. Mater. 323, 268 (2003).

31. D.J. Bacon, Yu.N. Osetsky and Z. Rong, unpublished work.

32. F. Gao, H. Heinisch, R.J. Kurtz, Yu.N. Osetsky, R.G. Hoagland, Phil. Mag. 85619 (2005).

33. D.J. Bacon, U.F. Kocks and R.O. Scattergood, Phil.Mag. 261242 (1973).

34. Y.N. Osetsky and D.J. Bacon, J. Nucl. Mater. 323268 (2003).

35. E. Bitzek and P. Gumbsch, Mat. Sci. and Eng. A 387-389 11 (2004). 


\section{Figure captions}

Fig. 1. Schematic illustration of the edge dislocation and SIA loop in one periodic cell. The sense of positive applied stress resolved shear stress, $\tau$, is indicated by the block arrows.

Fig. 2. Visualisations of the spontaneous glide and absorption process of a 37-SIA loop on the edge dislocation at $\mathrm{T}=0 \mathrm{~K}$. The value of applied strain, $\varepsilon$, corresponding to the abscissa of Fig. 3 is indicated.

Fig. 3. $\tau$ versus $\varepsilon$ plots for the glide and absorption process for a 37-SIA loop. The molecular statics (MS) simulations for $\mathrm{T}=0 \mathrm{~K}$ are for $\Delta \varepsilon$ increments of either 2 or $10 \times 10^{-5}$. The MD simulation is for $\mathrm{T}=100 \mathrm{~K}$ and $\dot{\varepsilon}=2 \times 10^{6} \mathrm{~s}^{-1}$.

Fig. 4. $\tau_{\mathrm{c}}$ versus $\mathrm{T}$ for 37-SIA and 331-SIA loops at various values of $\dot{\varepsilon}$ in units $10^{6} \mathrm{~s}^{-1}$. The MS $(\mathrm{T}=0 \mathrm{~K})$ value for the small loop is the maximum on the MS plots in Fig. 3.

Fig. 5. Visualisations of the spontaneous glide and transformation process of a 331-SIA loop at $\mathrm{T}=300 \mathrm{~K}$ and $\dot{\varepsilon}=20 \times 10^{6} \mathrm{~s}^{-1}$. The [010] segment has formed in (b) and is seen to glide down as the dislocation side arms in screw orientation glide down in (c) and (d).

Fig. 6. Schematic illustration of the processes observed in Fig. 5. The line arrows and index arrows show the positive line direction and Burgers vector as given by the $\mathrm{RH} / \mathrm{FS}$ convention.

Fig. 7. Visualisations of the interaction process for a 331-SIA loop at $\mathrm{T}=100 \mathrm{~K}$ and $\dot{\varepsilon}=$ $5 \times 10^{6} \mathrm{~s}^{-1}$. The [010] segment has formed in (a) and two dislocation side arms in screw orientation have been drawn out and started to cross-slip towards each other in (b).

Fig. 8. $\tau$ versus $\varepsilon$ plots for a 331-SIA loop at two temperatures and a 339-vacancy void for $\dot{\varepsilon}=5 \times 10^{6} \mathrm{~s}^{-1}$ at $\mathrm{T}=300 \mathrm{~K}$. 


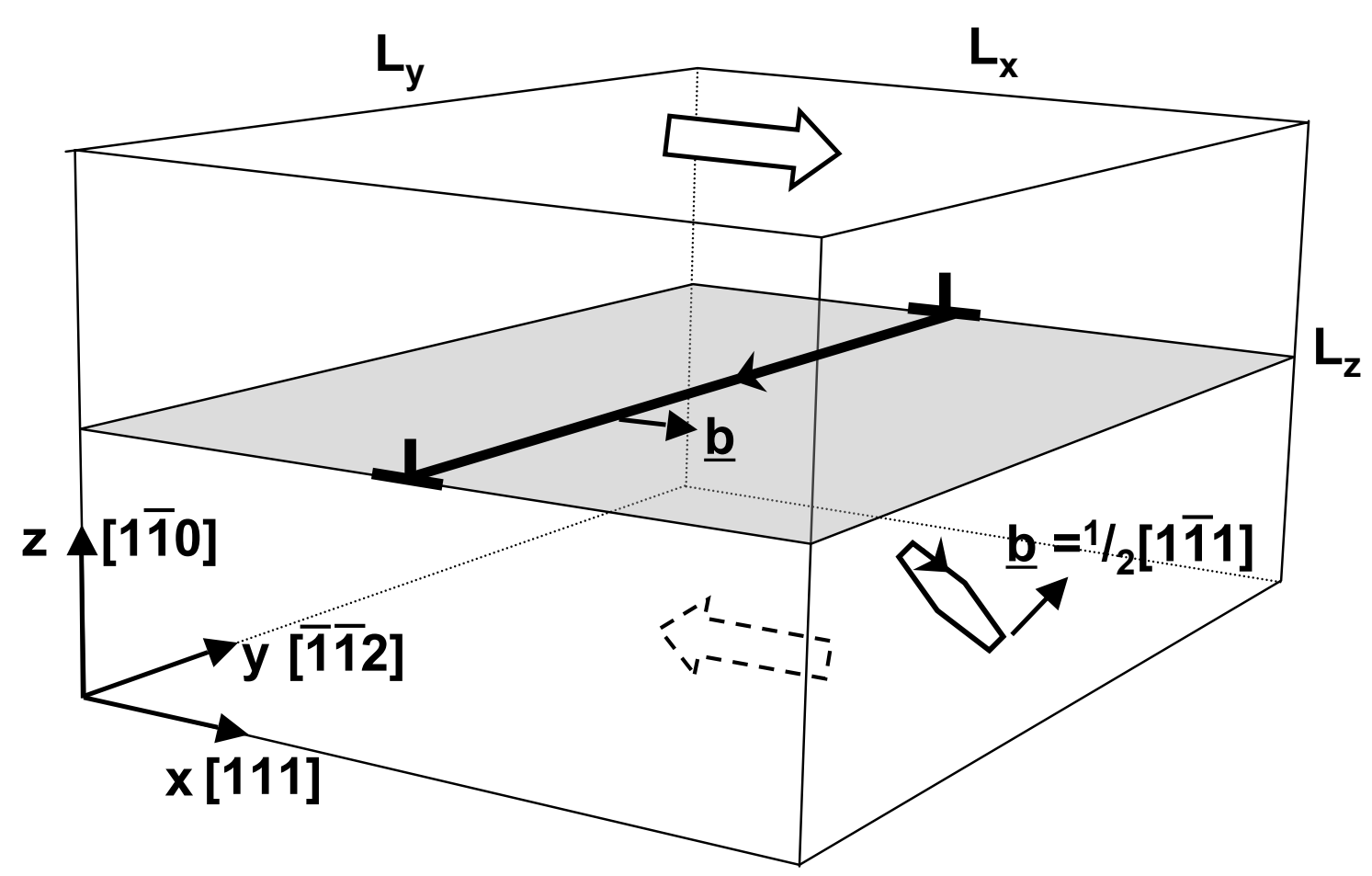

Fig. 1. Schematic illustration of the edge dislocation and SIA loop in one periodic cell. The sense of positive applied stress resolved shear stress, $\tau$, is indicated by the block arrows. 


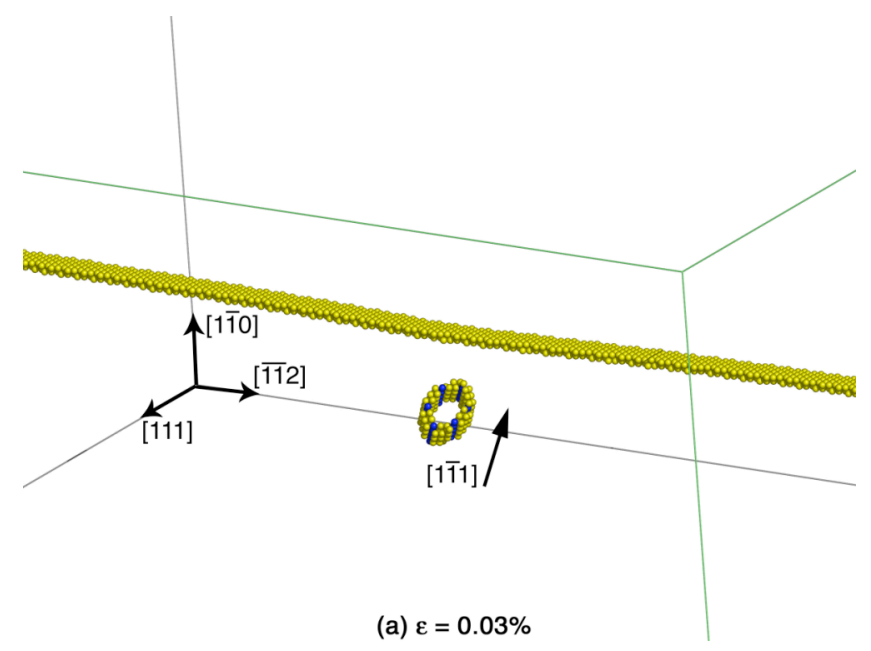

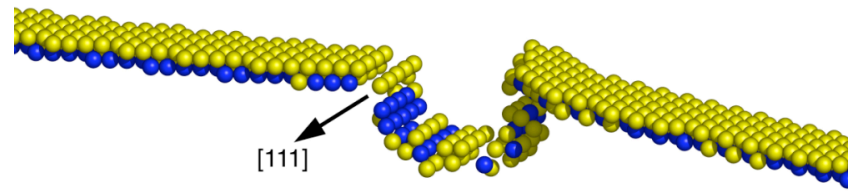

(b) $\varepsilon=0.214 \%$

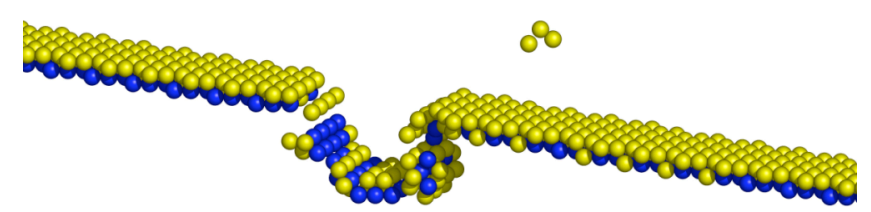

(c) $\varepsilon=0.234 \%$

Fig. 2. Visualisations of the spontaneous glide and absorption process of a 37-SIA loop on the edge dislocation at $\mathrm{T}=0 \mathrm{~K}$. The value of applied strain, $\varepsilon$, corresponding to the abscissa of Fig. 3 is indicated. 


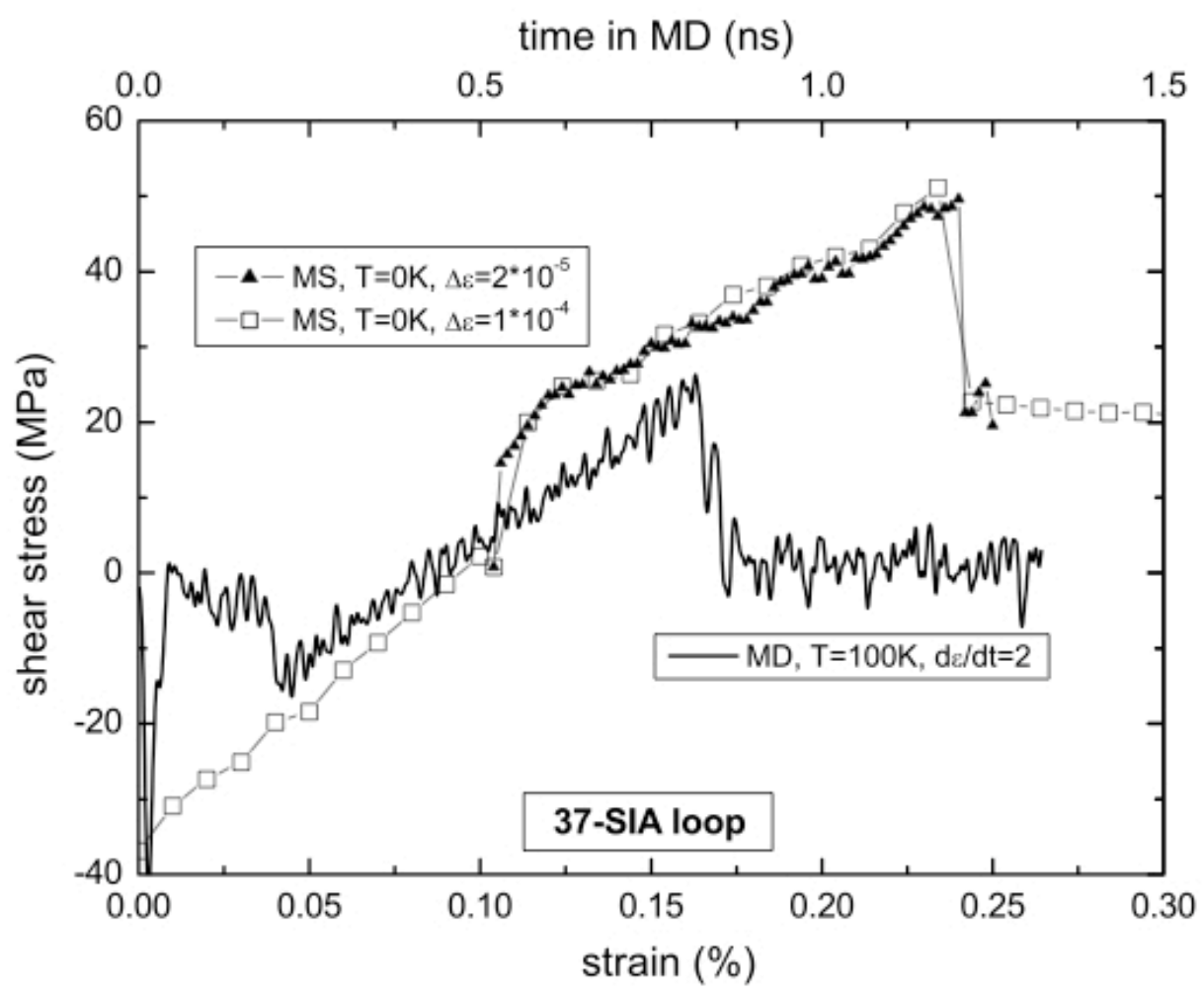

Fig. 3. $\tau$ versus $\varepsilon$ plots for the glide and absorption process for a 37-SIA loop. The molecular statics (MS) simulations for $\mathrm{T}=0 \mathrm{~K}$ are for $\Delta \varepsilon$ increments of either 2 or $10 \times 10^{-5}$. The MD simulation is for $\mathrm{T}=100 \mathrm{~K}$ and strain rate $=2 \times 10^{6} \mathrm{~s}^{-1}$.

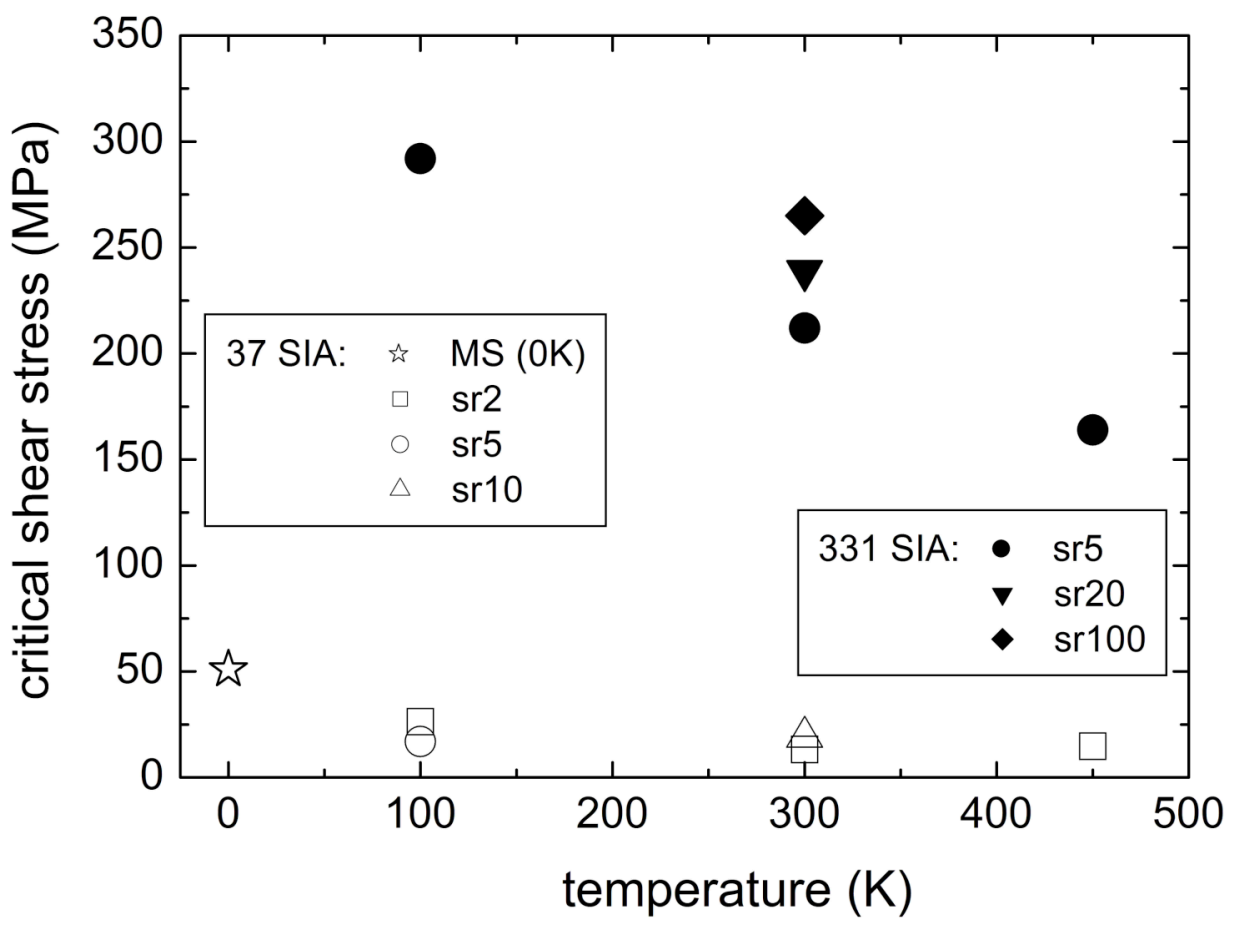

Fig. 4. $\tau_{c}$ versus $\mathrm{T}$ for 37-SIA and 331-SIA loops at various values of in units $10^{6} \mathrm{~s}^{-1}$. The MS $(\mathrm{T}=0 \mathrm{~K})$ value for the small loop is the maximum on the MS plots in Fig. 3. 


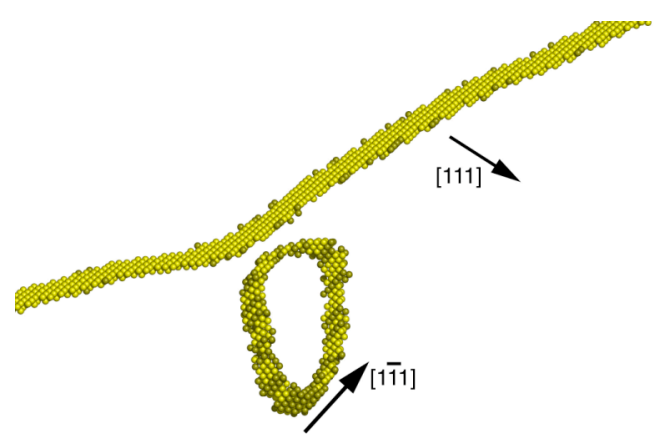

(a) $t=50 p s$

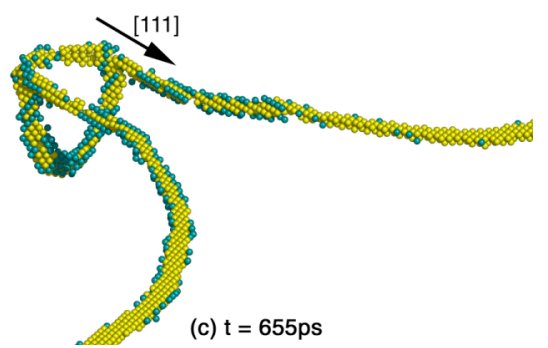

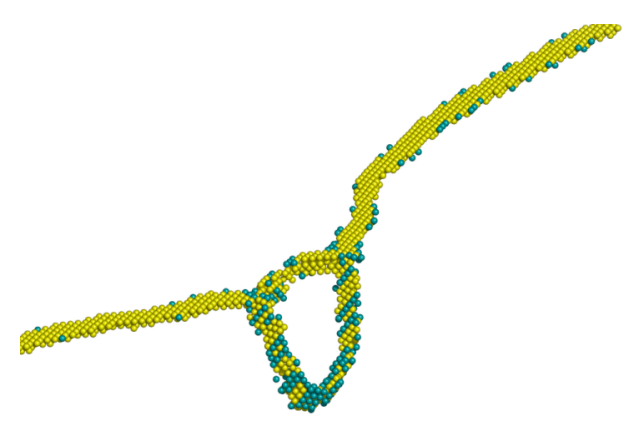

(b) $\mathrm{t}=55 \mathrm{ps}$

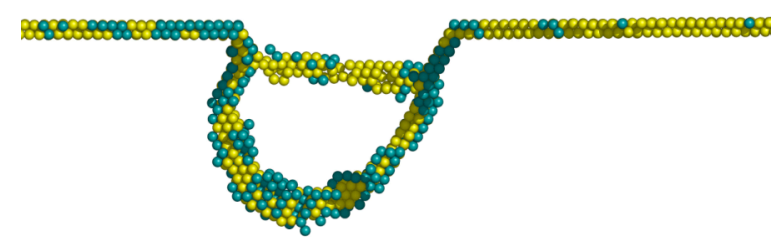

(d) $t=655 p s$

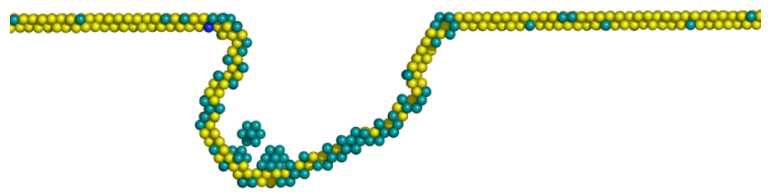

(e) $t=765 p s$

Fig. 5. Visualisations of the spontaneous glide and transformation process of a 331-SIA loop at $\mathrm{T}=300 \mathrm{~K}$ and strain rate $=20 \times 10^{6} \mathrm{~s}^{-1}$. The [010] segment has formed in (b) and is seen to glide down as the dislocation side arms in screw orientation glide down in (c) and (d). 

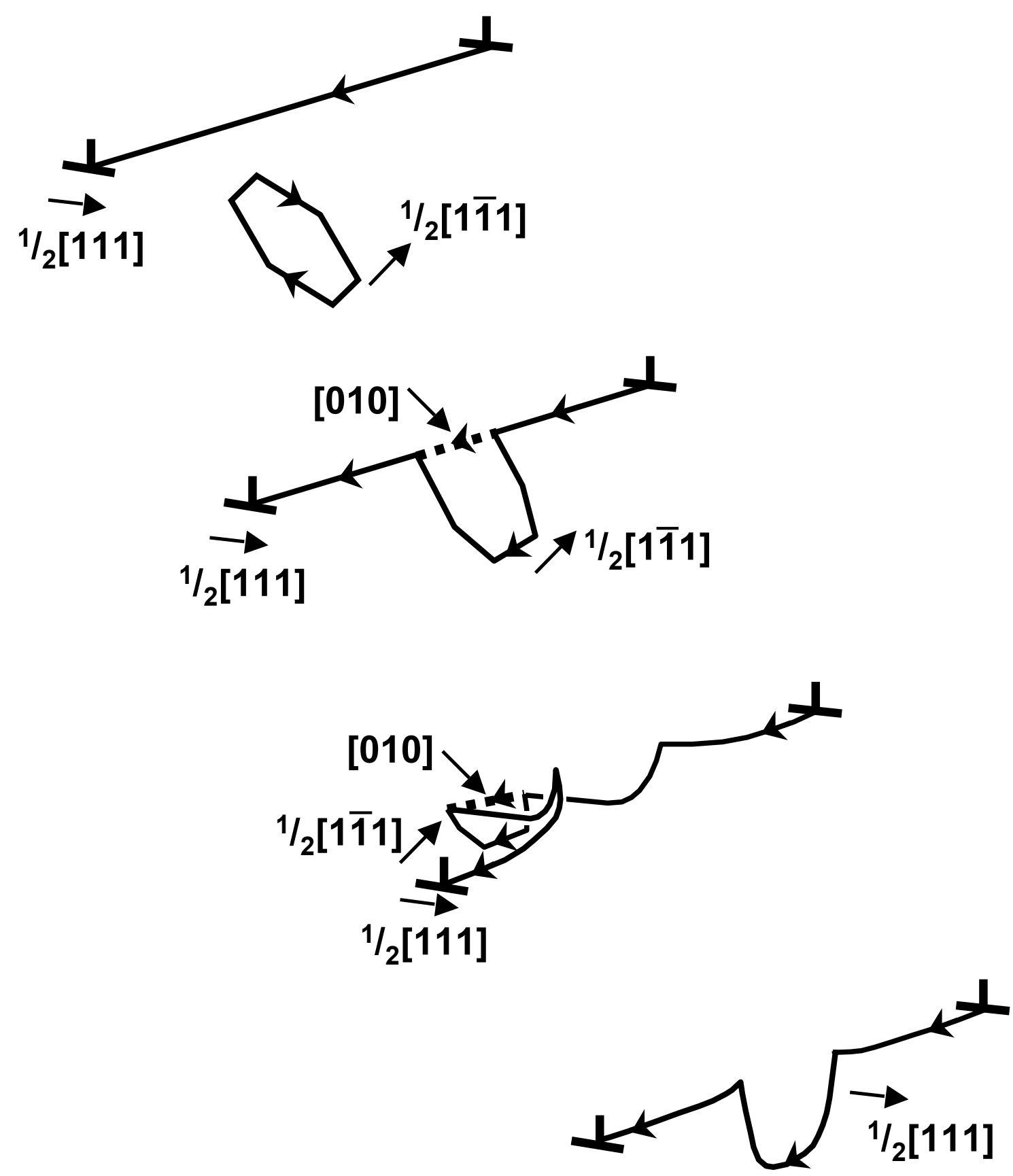

Fig. 6. Schematic illustration of the processes observed in Fig. 5. The line arrows and index arrows show the positive line direction and Burgers vector as given by the RH/FS convention. 


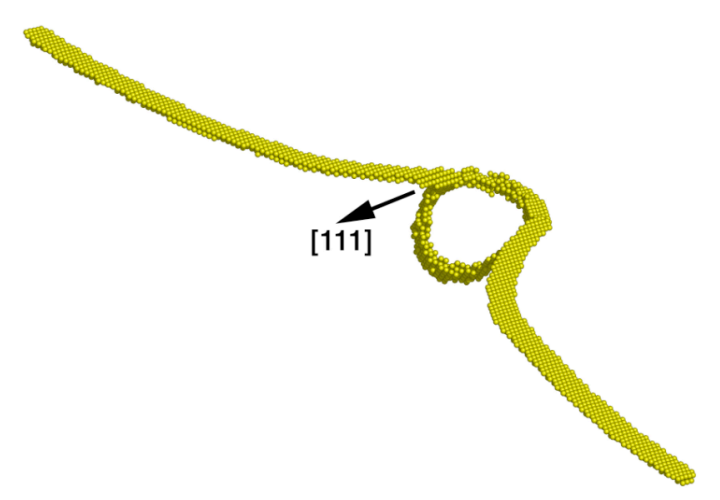

(a) $\mathrm{t}=1.4 \mathrm{~ns}, \tau=95 \mathrm{MPa}$

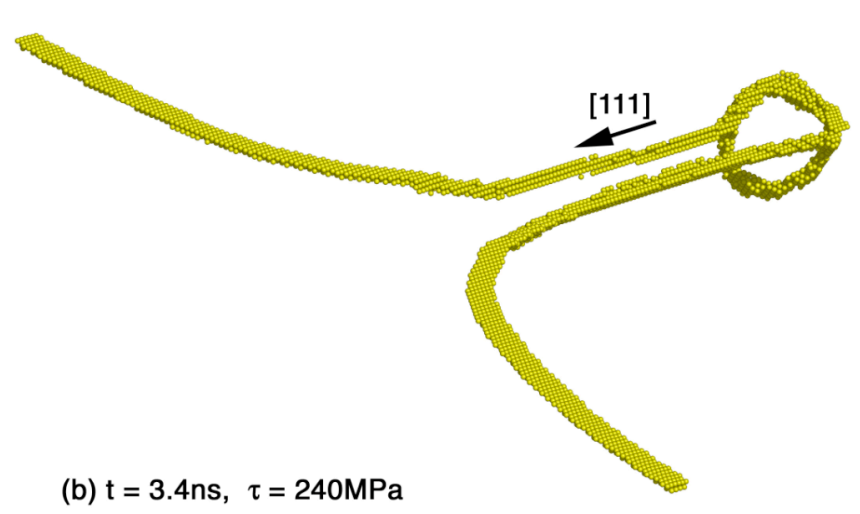

Fig. 7. Visualisations of the interaction process for a 331-SIA loop at $\mathrm{T}=100 \mathrm{~K}$ and strain rate $=5 \times 10^{6} \mathrm{~s}^{-1}$. The [010] segment has formed in (a) and two dislocation side arms in screw orientation have been drawn out and started to cross-slip towards each other in (b). 


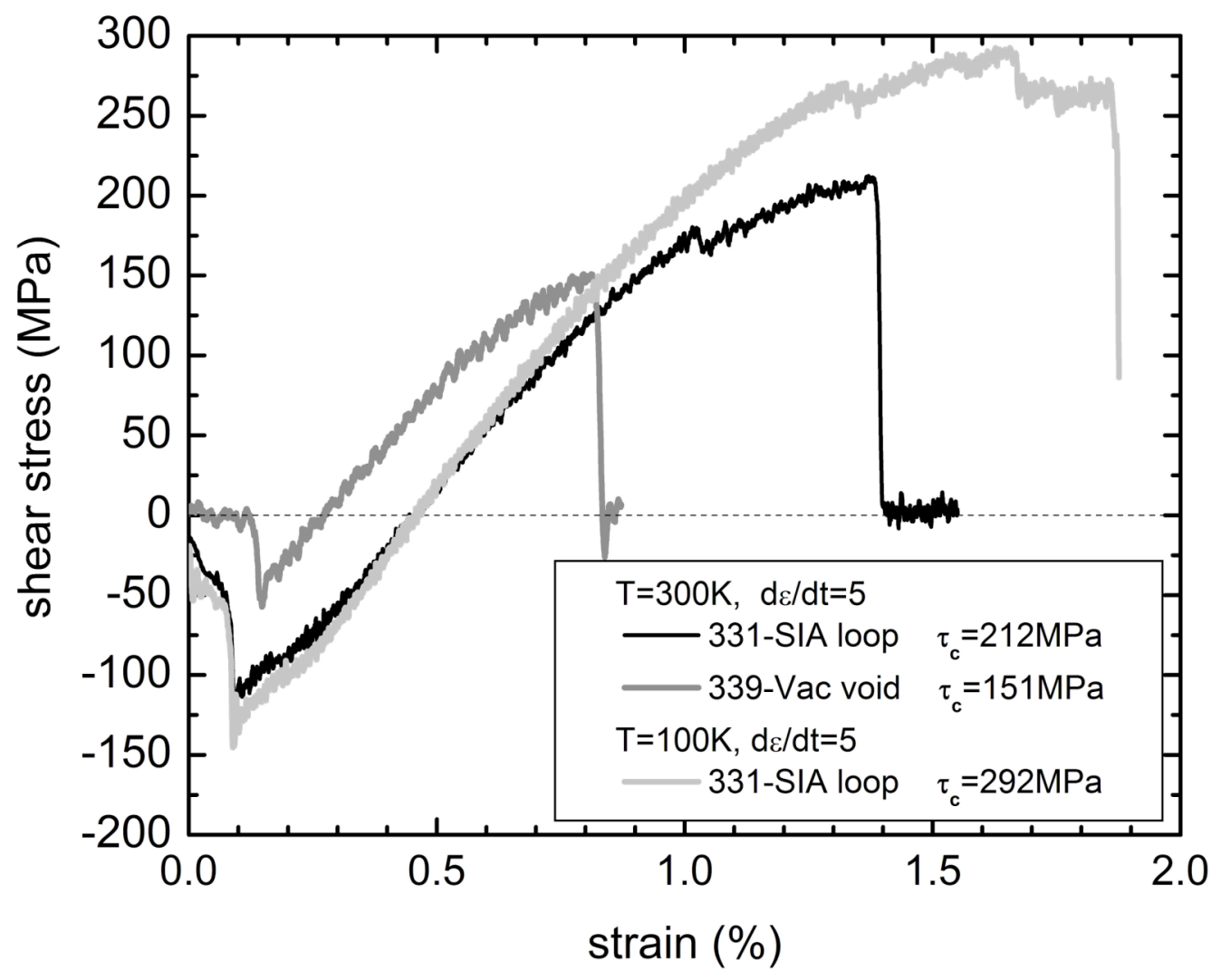

Fig.8. $\tau$ versus $\varepsilon$ plots for a 331-SIA loop at two temperatures and a 339-vacancy void for strain rate $=5 \times 10^{6} \mathrm{~s}^{-1}$ at $\mathrm{T}=300 \mathrm{~K}$. 


\title{
Computer simulation of reactions between an edge dislocation and glissile self-interstitial clusters in iron
}

\author{
D.J. Bacon ${ }^{1}$, Yu.N. Osetsky ${ }^{2}$ and Z.Rong ${ }^{1}$
}

1) Materials Science and Engineering, Department of Engineering, The University of Liverpool, Liverpool L69 3GH, UK.

2) Computer Science and Mathematics Division, Oak Ridge National Laboratory, P. O. Box 2008, Oak Ridge, TN 37831-6158, USA.

Clusters of self-interstitial atoms (SIAs) are formed in metals by high-energy displacement

\section{ABSTRACT} cascades, often in the form of small dislocation loops with a perfect Burgers vector, $\boldsymbol{b}$. Atomic-scale computer simulation is used here to investigate their reaction with an edge dislocation gliding in $\alpha$-iron under stress for the situation where $\boldsymbol{b}$ is inclined to the dislocation slip plane. $\boldsymbol{b}$ of small loops (37 SIAs here) changes spontaneously and the interstitials are absorbed as a pair of superjogs. The line glides forward at critical stress $\tau_{\mathrm{c}}$ when one or more vacancies are created and the jogs adopt a glissile form. A large loop (331 SIAs here) reacts spontaneously with the dislocation to form a segment with $\boldsymbol{b}=$ $\langle 100\rangle$, which is sessile on the dislocation slip plane, and as applied stress increases the dislocation side arms are pulled into screw orientation. At low temperature $(100 \mathrm{~K})$, the $\leq 100>$ segment remains sessile and the dislocation eventually breaks free when the screw dipole arms cross-slip and annihilate. At $300 \mathrm{~K}$ and above, the segment can glide across the loop and transform it into a pair of superjogs, which become glissile at $\tau_{c}$. Small loops are weaker obstacles than voids with a similar number of vacancies, large loops are stronger, Irrespective of size, the interaction processes leading to superiogs are efficient for absorption of SIA clusters from slip bands, an effect observed in flow localisation.

Corresponding author: D.J. Bacon (djbacon@liv.ac.uk)

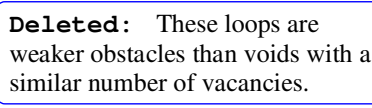

Deleted: obstacles than voids with a similar number of vacancies Deleted: is

Deleted: II

Keywords: Computer simulation, dislocation loop, interstitial cluster, iron, radiation damage 


\section{Introduction}

Exposure of metals to fast-neutron irradiation can cause a substantial increase in yield stress and a reduction in ductility due to the interaction of dislocations with obstacles on or near their slip plane. The obstacles are formed largely by point defect clusters created in displacement cascades. Molecular dynamics (MD) computer simulations have shown that the self-interstitial atom (SIA) component of primary radiation damage is mainly in the form of platelets of closely-packed, parallel crowdions that are equivalent to small, nanometre-scale interstitial dislocation loops with perfect Burgers vector, $\boldsymbol{b}$, parallel to the crowdion axis, e.g. [1,2]. Atomistic simulations of a variety of BCC, FCC and HCP metals have shown that such loops are glissile and move in one dimension parallel to the crowdion axis by thermally-activated events with a low activation energy of $\sim 0.02 \mathrm{eV}$ [35]. They have a long-range strain field and can interact with dislocations by either intersecting their slip plane or gliding to decorate them in regions where they are attracted by the dislocation stress field. The latter possibility has support from experiment, e.g. [6] and modelling, e.g. [7,8], Further, the interaction of gliding dislocations with loops clearly influences the flow stress and ductility of irradiated metals, and is believed to play an important role in flow localisation and the formation of slip channels that appear to be cleared of radiation damage debris [9]

Decoration of dislocation sources by 'atmospheres' of interstitial loops led Singh and co-workers [10] to argue that the increase in the upper yield stress and the subsequent yield drop are related to the stress necessary to unlock dislocations from the loops that decorate them. Estimates of the unlocking stress for a straight dislocation were found to be consistent with experiment. A continuum dislocation dynamics method was later used to determine the stress for a flexible dislocation to break away from rows of loops below the slip plane and confirmed the earlier estimates $[11,12]$. These treatments assumed the interstitial loops to be static and unable to glide with a dislocation, whereas perfect loops are intrinsically glissile and those nearest the slip plane not only exert the largest force on the dislocation but also experience the largest force tending to make them glide. This was pointed out by Makin [13], who calculated the long-range elastic interaction between a

Deleted: (?? Refs for decoration?)

Deleted: (?? Okay? Nasr work?)

Deleted: 8

Deleted: (?? Refs for this?)

Deleted: 9,10

Deleted: 1

Deleted: 2 
with the same $\boldsymbol{b}$ may be swept along with it, although the effect could not be quantified in the absence of information on the force to move a loop at the atomic scale.

The present work is part of a series of atomic-scale studies of the dynamics of dislocation behaviour in the presence of jnterstitial loops in $\alpha$-iron (Fe), Loops with $\boldsymbol{b}=$ $1 / 2<111>$ and $<100>$ grow during irradiation of this metal. The origin of the latter, which have the larger elastic energy, is unclear. It has been proposed that both sets could result by shear from a common $1 / 2<110>$ nucleus [14], or that two intersecting $1 / 2<111>$ clusters can react to form a $<100>$ loop [15]. However, neither mechanism has yet been demonstrated to occur and the $1 / 2<111\rangle$ configuration has lower energy than $\langle 100\rangle$ using all currently available interatomic potentials. Since $1 / 2<111>$ SIA clusters arise in irradiated iron and other BCC metals, we have concentrated on them in the first part of this study. In any case, it is not obvious a priori, which creates the stronger obstacle to glide of a dislocation with $b=1 / 2<111>$, because the dislocation can react favourably with a $1 / 2<111>$ loop to form a $<100>$ segment, which can be sessile (see later), whereas the favourable reaction with a $\leq 100>$ loop results in another $1 / 2<111>$ segment, which is glissile. Thus, both loop types need to be studied and we will report on treatment of $<100>$ loops in a second part.

Previously, the interaction of a $1 / 2<111>\{110\}$ edge dislocation gliding under applied stress with sets of $1 / 2<111>$ SIA clusters of size $\sim 1 \mathrm{~nm}$ distributed below the extra half-plane was simulated for a range of temperature $[16,17]$. It was found that a row of loops can be dragged at almost the free-flight velocity of the dislocation $\left(\sim 100 \mathrm{~ms}^{-1}\right.$ for $10 \mathrm{MPa}$ at $300 \mathrm{~K})$. A quantitative model for this, based on a drag coefficient derived from the diffusivity of interstitial loops, was presented, and the conditions under which a dislocation breaks away from a row of glissile loops was determined._Perfect dislocation loops in this metal have $\boldsymbol{b}$ equal to one of the four possible vectors $1 / 2<111>$, but only two of them are parallel to the $\{110\}$ slip plane of a dislocation and were considered for drag. Glissile loops with one of the other two $\boldsymbol{b}$ s can move to jntersect the dislocation glide plane, however, and cause direct dislocation-dislocation reaction. This latter process is modelled in the present work and its dependence on temperature, $\mathrm{T}$, applied shear strain rate, ś, and loop size analysed. We have again considered the edge dislocation.

Although it is well known that glide of screw dislocations controls slip in BCC metals at low $\mathrm{T}$, it should be noted that edge dislocations have to interact/absorb/overcome loops for plastic flow to occur at any temperature. Their mechanisms therefore have to be

Deleted: glissile

Formatted: Not Highlight

Deleted:

Formatted: Not Highlight

Formatted: Font: Bold,

Formatted: Not Highlight

Formatted: Not Highlight

Formatted: Not Highlight

Formatted: Not Highlight

Formatted: Not Highlight

Formatted: Not Highlight

Formatted: Not Highlight

Formatted: Font: Italic, Not Highlight

Formatted: Not Highlight

Formatted: Font: Bold,

Formatted: Not Highlight

Formatted: Not Highlight

Formatted: Not Highlight

Deleted: Initially

Deleted: $\mathrm{n}$

Deleted: in $\alpha$-iron and copper

Deleted: 4

Deleted: 3

Deleted: 5

Deleted: 4

Deleted: in $\mathrm{Fe}$

Deleted: The simulations

concentrated on the slip system

$1 / 2<111>\{110\}$ in $\alpha$-iron.

Deleted:

Deleted: and

Deleted:

Formatted: No underline

Formatted: No underline 
investigated since there is no reason to suppose a priori that they are not important. Furthermore, dislocation glide can result in the production of cleared channels, as noted above, and, although some static and dynamic simulations of screw-1/2<111 $>$ loop interaction have been reported $[18,19]$, we are not aware of evidence that screw dislocations absorb/remove loops to result in clear band formation.

The method employed here is summarised in section 2 and the results presented in section 3. Section 4 contains a discussion of the investigation, including an assessment of its consequences for understanding the effects of irradiation on plasticity in iron. We also compare the present results with those of a very recent MD simulation of dislocation-loop interaction in iron with the same geometry as used here by Nomoto et al. [20] and with a qualitatively similar study of dislocation-loop interaction in the FCC metal nickel by Rodney and Martin $[21,22]$.

\section{Method and geometry}

The method developed by Osetsky and Bacon [23], which treats a periodic array of edge dislocations, was employed. The $\mathrm{x}, \mathrm{y}$ and $\mathrm{z}$ axes of the simulated crystal were oriented along [111], [ $\overline{1} \overline{1} 2]$ and [1 $\overline{1} 0]$ directions, as illustrated in Fig. 1. Periodic boundary conditions were employed in the $\mathrm{x}$ and $\mathrm{y}$ directions, corresponding to the direction of $\boldsymbol{b}$ and the line direction, respectively, and fixed conditions were used across the $\mathrm{z}$ boundaries. Choice of crystal dimensions is important for modelling dislocation motion because the size, $L_{x}$, along the $x$-axis should be large enough for interactions between the dislocation and its images to be insignificant [23]. We used $\mathrm{L}_{\mathrm{x}}=120 \mathrm{~b}(\sim 29.8 \mathrm{~nm}$ for Fe with model lattice parameter $\mathrm{a}_{0}=0.2867 \mathrm{~nm}$ at temperature $\mathrm{T}=0 \mathrm{~K}$ ); the period, $\mathrm{L}_{\mathrm{y}}$, defines the inter-cluster spacing and was $59 \sqrt{6} \mathrm{a}_{0}(\sim 41.4 \mathrm{~nm})$; and $\mathrm{L}_{\mathrm{z}}$ was $49 \sqrt{ } 2 \mathrm{a}_{0}(\sim 19.9 \mathrm{~nm})$. The total number of mobile atoms in the MD cell was $\sim 2.1 \mathrm{M}$.

Rigid blocks of atoms were used at the z-axis boundaries to apply shear strain, $\varepsilon$, by displacement of the $+\mathrm{z}$ block. The corresponding applied shear stress, $\tau\left(=\tau_{\mathrm{xz}}\right)$, was computed from the shear force on this block due to the free atoms of the inner region (see [23]). Molecular statics (MS) relaxation, i.e. potential energy minimisation, was used to

\begin{tabular}{|c|}
\hline Deleted: 16 \\
\hline Deleted: 5 \\
\hline Deleted: 17 \\
\hline Deleted: 6 \\
\hline Deleted: ,18 \\
\hline Deleted: 7 \\
\hline Deleted: and \\
\hline 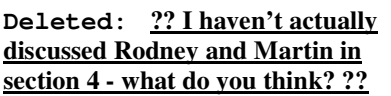 \\
\hline Deleted: 19 \\
\hline Deleted: 8 \\
\hline
\end{tabular}
simulate athermal loading at $\mathrm{T}=0 \mathrm{~K}$ under strain increasing in increments $\Delta \varepsilon=2$ to $10 \times 10^{-}$ 5. Molecular dynamics (MD) with timestep 2-5fs was used for constant-strain-rate 
deformation at $\mathrm{T}>0 \mathrm{~K}$, with $\_$s in the range $2-100 \times 10^{6} \mathrm{~s}^{-1}$ and $\mathrm{T}$ in the range $100-450 \mathrm{~K}$, as Deleted: $\dot{\varepsilon}$ defined by the mean atomic kinetic energy. Thermal expansion was treated by changing $\mathrm{a}_{0}$ until the total pressure fluctuated around zero.

The Finnis-Sinclair-type interatomic potential for Fe of Ackland et al. [24] was used. The SIA clusters/loops were created in the model by inserting $<111\rangle$ dumbbells after the dislocation had been formed and relaxed ${ }_{2}$ and then relaxing the model again to minimise the potential energy. They contained $\mathrm{N}$ interstitials and were of hexagonal shape with sides of length $d=a_{0}(2 N)^{1 / 2} / 3$ along $\langle 112>$ directions. Values $N=37$ and 331 were chosen, i.e. $\mathrm{d}=0.82$ and $2.46 \mathrm{~nm}$, respectively. The centre of the cluster was positioned a distance $\mathrm{H}$ below the slip plane, as depicted in figure 1. Values of $\mathrm{H}$ equal to 11, 22 and $33 \mathrm{a}_{0}$ were used. The two loop Burgers vectors $1 / 2[1 \overline{1} 1]$ and $1 / 2[\overline{1} 11]$ are inclined to the (1 10$)$ slip plane, but they are symmetric with respect to the dislocation, so only one need be considered. A loop with $\boldsymbol{b}=1 / 2[1 \overline{1} 1]$ is shown schematically in Fig. 1 .

\section{Results}

\subsection{Reaction at $\mathrm{T}=0 \mathrm{~K}$}

Under the attractive field of the dislocation, and even in the absence of thermal motion of the atoms, small SIA loops glide over the $\mathrm{H}$ range considered to meet the dislocation as it moves under strain on its slip plane. (The thickness of cleared channels was not a concern of this work, but the band of interaction over which loops can glide to an edge dislocation must at least $33 \mathrm{a}_{0}$, even at $\mathrm{T}=0 \mathrm{~K}$. It was not feasible to model larger crystals to investigate this dimension further.) The dislocation actually bows forward as a loop approaches in order to assist the favourable reaction. Fig. 2(a) shows a visualisation of the initial dislocation line and 37-SIA cluster viewed from the front of the model crystal in Fig. 1. The dislocation has already started to bow forward slightly and as it moves further under the applied strain the loop slips on its glide cylinder along [1 111$]$ to meet it. The axis of the crowdions then changes to [111], i.e. $\boldsymbol{b}$ of the SIA loop rotates to be the same as that of the dislocation line. The newly-formed pair of superjogs restricts the slip of the dislocation (Fig. 2(b)) until the SIAs that form it reorganise by self-climb and emission of a vacancy in the crystal to give glissile segments on $\{110\}$ or $\{112\}$ planes of 
the [111] zone axis, as seen in Fig. 2(c). The jogged dislocation then continues to glide with little hindrance.

The relationship between $\tau$ and $\varepsilon$ during the process is plotted in Fig. 3. In the absence of any other defect, the edge dislocation glides on a $\{110\}$ plane in the model at $\mathrm{T}$ $=0 \mathrm{~K}$ under applied resolved shear stress of about $25 \mathrm{MPa}$ [23]: this is the Peierls stress, $\tau_{\mathrm{P}}$. As the dislocation approaches the periodic row of SIA clusters, it is initially attracted towards them $\left(\tau<\tau_{\mathrm{P}}\right)$ and becomes pinned by the double superjogs formed by the reaction. $\tau$ rises as $\varepsilon$ increases until reaching a maximum (i.e. critical) stress $\tau_{c}=51 \mathrm{MPa}$, at which stage a vacancy is created and the superjogs become glissile on the $\boldsymbol{b}=1 / 2[111]$ system and $\tau$ falls to $\tau_{\mathrm{P}}$. The process described does not depend on the increment $\Delta \varepsilon$ used here, as seen from the two sets of data in Fig. 3.

The simulations for $\mathrm{T}=0 \mathrm{~K}$ provide information on the equilibrium (minimum potential energy) structure at each strain increment, and the configurations are equivalent to those that would be obtained by minimising the elastic energy in the continuum approximation. However, they do not necessarily reveal information about the atomic mechanisms that would occur in a real metal where thermal effects assist the reaction process, For this reason, most modelling has been done using MD, as described in the following section.

\subsection{Reaction at $T>0 K$}

\subsubsection{Small loops}

The aim of this part of the study was to examine the effect of cluster size, temperature and_ś on the reaction and strengthening mechanism. The 37-SIA cluster is considered first. Its interaction with the edge dislocation has been investigated for $\mathrm{T}=$ 100,300 and $450 \mathrm{~K}$ in a model with applied_s values in the range $2-10 \times 10^{6} \mathrm{~s}^{-1}$. (For the dislocation density $\left(\mathrm{L}_{\mathrm{x}} \mathrm{L}_{\mathrm{z}}\right)^{-1}$ used here, this corresponds to dislocation velocity in steady state of $5-24 \mathrm{~ms}^{-1}$.) Under all conditions considered, the cluster glides to meet the dislocation and the axis of its crowdions rotates from [1 $1 \overline{1} 1]$ to [111] when the cores of the two defects react. This results in creation of a pair of superjogs, which hinders slip of the dislocation and results in increasing $\tau$ until the interstitials in the superjogs reorganise by emitting a vacancy and form glissile segments on slip planes of the [111] zone. The 
before-and-after structures are the same as those for $\mathrm{T}=0 \mathrm{~K}$ in Fig. 2. Unsurprisingly, the critical stress, $\tau_{\mathrm{c}}$, is less than at $0 \mathrm{~K}$. This is illustrated by the $\tau$ versus $\varepsilon$ and time, $\mathrm{t}$, plot for $\mathrm{T}=100 \mathrm{~K}$ and $\boldsymbol{s}_{-}=2 \times 10^{6} \mathrm{~s}^{-1}$ included in Fig. 3 . The noise in the plot arises because of the non-zero temperature, but it can be seen that the dislocation, which glides at a stress of only a few MPa at this T and ś, is initially attracted to the loop $(\tau<0)$, is then held back by the superjogs and eventually at $\mathrm{t} \sim 0.8 \mathrm{~ns}$ glides forward when the $1 / 2[111]$ superjogs become glissile: this final step takes place at a smaller stress (26MPa) and strain than at $0 \mathrm{~K}$.

The data for $\tau_{\mathrm{c}}$ for the various conditions of $\mathrm{T}$ and $\mathrm{s}_{\mathrm{s}}$ are plotted in Fig. 4. It is seen that $\tau_{\mathrm{c}}$ is almost independent of both parameters when $\mathrm{T}>0 \mathrm{~K}$. Visualisation of the defect configuration during the loop transformation shows that rotation of $\boldsymbol{b}$ does not occur until the cores of the dislocation and loop meet. Furthermore, it is not the process that controls $\tau_{c}$, for $\tau$ continues to increase beyond this rotation stage. Glide of the dislocation and absorbed loop occurs when atoms in segments of the core of the transformed loop rearrange at $\tau_{\mathrm{c}}$ to form glissile superjogs.

\subsubsection{Large loops}

Loops containing 37 SIAs are typical of those formed directly in the primary displacement cascade process, which is consistent with the mean size $\sim 1 \mathrm{~nm}$ observed experimentally at low irradiation dose $\left(\sim 10^{-3} \mathrm{dpa}\right)[25-27]$. These loops are highly mobile and can move by mutual attraction to form larger dislocation loops, as seen in MD simulations [28] and, therefore, loop size increases with irradiation dose, reaching $\sim 5 \mathrm{~nm}$ at $\sim 1 \mathrm{dpa}$ [25-27] Thus, we now consider loops containing 331 interstitials they have $\mathrm{d}=$ $2.46 \mathrm{~nm}_{2}$ which is equivalent to diameter $\sim 5 \mathrm{~nm}$.

Five frames showing the interaction at $300 \mathrm{~K}$ for $s=20 \times 10^{6} \mathrm{~s}^{-1}$ are presented in Fig. 5. Initially, the loop glides towards the dislocation glide plane and its upper segment attracts the dislocation, which bows forward (Fig. 5(a)). When they meet (Fig. 5(b)), the Burgers vector of the upper segment is transformed by the reaction

$$
1 / 2[111]+1 / 2[\overline{1} 1 \overline{1}]=[010],
$$

which is energetically-favourable according to Frank's rule. The remainder of the initial loop retains its $1 / 2[1 \overline{1} 1]$ Burgers vector. The [010] segment is sessile in the (1 $\overline{1} 0)$ slip

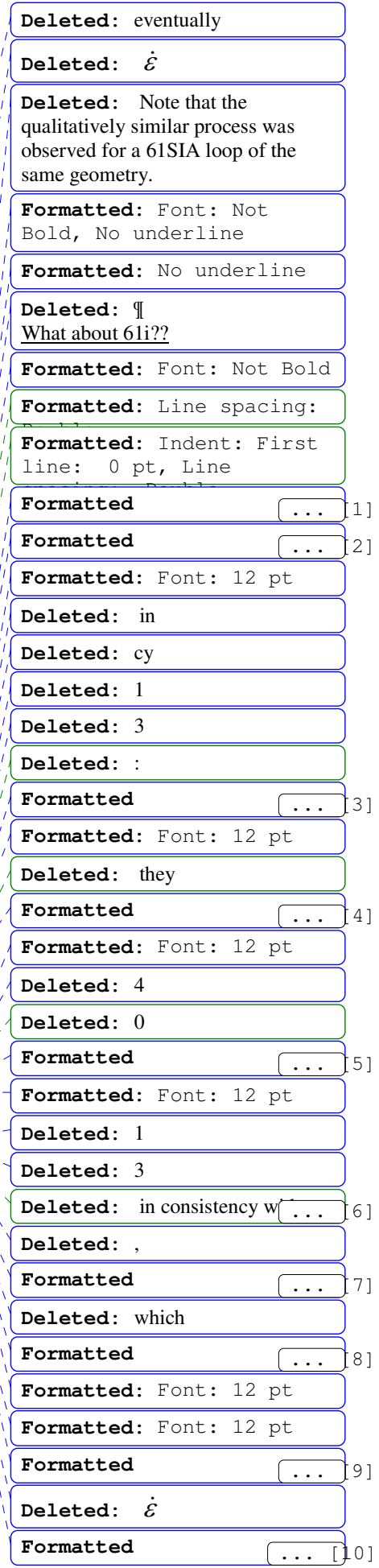


plane of the dislocation, but glissile in the inclined (101) plane. However, it is pinned at its ends by the junctions with the $1 / 2[111]$ and $1 / 2[\overline{1} 1 \overline{1}]$ lines, and is too short to bow under the applied stress. As $\tau$ increases, the $1 / 2[111]$ line segments pinned at the junctions are pulled into the screw orientation (Fig. 5(c)) and, assisted by the applied force on the [010] segment, cross-slip on (101) planes, thereby allowing the [010] segment to slip downwards on the (101) plane. This is shown in the view along $[\overline{1} \overline{1} \overline{1}]$ in Fig. 5(d). Eventually, at high enough applied stress, the downwards slip of the [010] dislocation and the [111] screw side arms completes the transformation of the loop into a pair of $1 / 2[111]$ superjogs on the gliding dislocation, wherein all 331 SIAs are contained (Fig. 5(e)). A few vacancies are formed in the crystal at the point when the dislocation glides forward at $\tau_{c}$, in a similar manner to the small loop above, resulting in additional SIAs in the jogs. The reaction and transformation is completed in less than $0.8 \mathrm{~ns}$ at this strain rate. It is shown in schematic representation in Fig. 6. The arrows denoting the direction of $\boldsymbol{b}$ are obtained using the RH/FS convention with the positive line sense indicated [29].

The maximum stress, $\tau_{c}$, for the process in Fig. 5 is $220 \mathrm{MPa}$ and the jogged dislocation line continues to glide at $\tau=12 \mathrm{MPa}$. The same reaction and transformation process occurred for the other two 8 at $300 \mathrm{~K}$ and at $450 \mathrm{~K}$. The value of $\tau_{\mathrm{c}}$ depends on $\mathrm{T}$ and $\underline{s}_{-}$, however, as shown by the data plotted in Fig. 4. The interaction was also simulated for $\mathrm{T}=450 \mathrm{~K}$ and $\underline{\boldsymbol{s}}=5 \times 10^{6} \mathrm{~s}^{-1}$, but with the sense of the applied strain reversed, i.e. the dislocation approached the loop from the right-hand side of the model in the schematic illustration of Fig. 1. The critical stress was the same as that in Fig. 4 and the transformation and unpinning processes were unchanged.

The interaction at $100 \mathrm{~K}$ and $\underline{\dot{s}}=5 \times 10^{6} \mathrm{~s}^{-1}$ resulted in $\tau_{\mathrm{c}}=290 \mathrm{MPa}$ (see Fig. 4) and had a different outcome. Two frames in the process are shown in Fig. 7. Creation of a [010] segment by the reaction of eq. (1) occurred again (Fig. 7(a)), but the segment was seen to be sessile in the loop plane at this low temperature and a long screw dipole formed on the $1 / 2[111]$ dislocation under increasing stress (Fig. 7(b)). The dipole eventually annihilated by cross-slip of its arms, which has started in Fig. 7(b), and the $1 / 2[1] 11]$ loop was restored. Thus, both the strength of large loops and the ease with which they are absorbed as superjogs depend on temperature via the mobility of $<100\rangle$ segments.

\section{Discussion}

Deleted: the

Deleted:

Deleted: $\overline{1} \overline{1} \overline{1}$
Deleted: 5

Deleted: 1

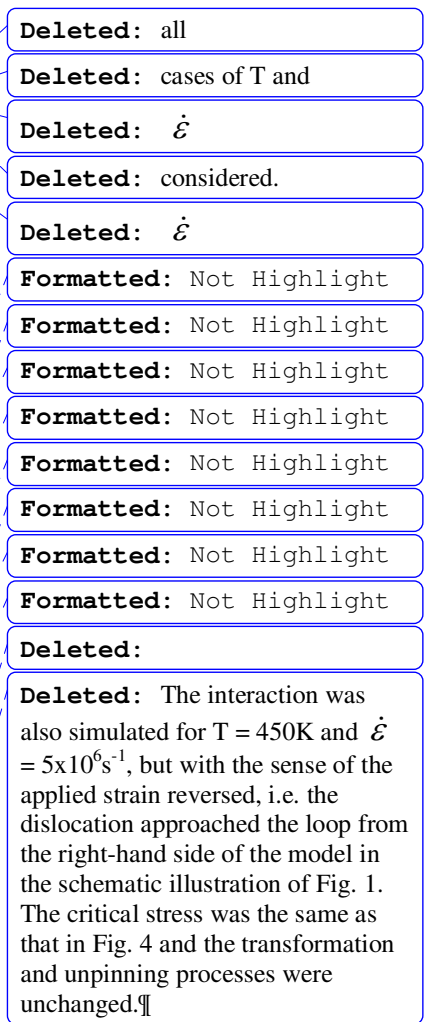


This research shows clearly that the interaction mechanism between an edge dislocation and a $1 / 2<111>$ interstitial loop whose glide cylinder intersects the dislocation slip plane depends on the size of the loop. Consequently, the obstacle strength provided by a loop against dislocation motion depends on loop size and, for large loops, also changes with temperature and applied_ś. Small loops (37_SIAs here) offer the least resistance because, even in the absence of thermal effects $(\mathrm{T}=0 \mathrm{~K})$, they are able to undergo rotation Deleted: $\dot{\varepsilon}$
Deleted: of the crowdion axis, $\boldsymbol{b}$, on meeting the dislocation and be absorbed on it as a double superjog. (A few simulations have been performed for 61-SIA loops, and the $\boldsymbol{b}$-rotation and loop absorption process is the same.) The maximum stress corresponds to the creation of point defects as the core of the jog segments reorganises to become glissile. The superjogs have only a small drag effect on the line after this in both statics and dynamics simulations.

This stress-assisted transformation occurs at $\tau_{\mathrm{c}}=51 \mathrm{MPa}$ at $0 \mathrm{~K}$ and between 13 and $27 \mathrm{MPa}$ at $\mathrm{T}>0 \mathrm{~K}$ when the inter-loop spacing, $\mathrm{L}_{\mathrm{y}}$, equals $41.4 \mathrm{~nm}$. This compares with $\tau_{\mathfrak{c}} \simeq$ $\underline{100 \text { and } 118} \mathrm{MPa}$ at $\mathrm{T}=0 \mathrm{~K}$ for an edge dislocation to cut through a row of spherical voids in iron containing a similar number (27 or 59) of vacancies and with the same spacing Thus, small dislocation loops are relatively weak obstacles compared with voids. Note, however, that all the SIAs are absorbed by the line in the form of a double superjog: only a few vacancies are absorbed by climb when a dislocation passes through a void at $T=0 \mathrm{~K}$ [30]. Furthermore, superjogs increase the interaction cross-section of a dislocation for reaction and/or annihilation with other defects in a crystal. Thus, the SIA-loop absorption process should be effective in assisting the creation of defect-free channels when slip occurs in irradiated iron.

This absorption effect for small loops is similar to that found in simulation of edge dislocation-SIA loop interaction in nickel by Rodney and Martin [21 22]. Loops with 4-37 interstitials and a $<110\rangle$ crowdion axis were absorbed by the dislocation, which is dissociated in the FCC structure, by rotation of their axis $(\boldsymbol{b})$. This resulted in either transformation into a pair of superjogs on the dislocation, as here, or attachment to one of the Shockley partials by means of a dislocation junction. Furthermore, recent simulations have shown that rotation of $\boldsymbol{b}$ also occurs for small clusters of crowdion SIAs gliding into contact with an edge dislocation of the prism-slip system in $\alpha$-zirconium [31]. This metal

\begin{tabular}{l} 
Deleted: 17 \\
Deleted: 6 \\
\hline Deleted: 18 \\
Deleted: 7 \\
Deleted: double \\
\hline Deleted: 2 \\
Deleted: 7 \\
Deleted: 6 \\
Deleted: 3
\end{tabular}


has the HCP crystal structure, and so the rotation-absorption process requiring relatively low stress seems quite general for loops with up to a few tens of defects. Note that rotation requires contact interaction with a dislocation: it does not occur for SIA clusters in isolation if they contain more than four or five interstitials [32]

The reaction with a large loop (331 SIAs here) provides a much stronger obstacle to dislocation motion than that with a small loop because spontaneous rotation of $\boldsymbol{b}$ when the two defects first meet does not occur. Instead, a segment with $\boldsymbol{b}=\langle 100\rangle$ is formed. It is sessile in the dislocation glide plane and can only glide across the loop plane and complete the transformation to $\boldsymbol{b}=1 / 2<111>$ when, under sufficiently high $\tau$, the dislocation side arms are pulled into screw orientation and then cross-slip (Fig. 6). $\tau_{c}$ is not only much higher but also more strongly temperature-dependent for this process. In fact, glide of the $\leq 100>$ segment does not occur at $100 \mathrm{~K}$, i.e. it is effectively immobile, and the high value of $\tau_{c}$ is controlled by cross-slip and annihilation of the arms of the $1 / 2<111>$ screw dipole. In this case, the original loop is restored at dislocation breakaway, rather than absorbed.

Unlike the situation for small obstacles, $\tau_{\mathrm{c}}$ for 331-SIA loops is higher than for voids with a similar number of vacancies. For example, $\tau_{\mathrm{c}}$ equals $150 \mathrm{MPa}$ at $\dot{s}=5 \times 10^{6} \mathrm{~s}^{-1}$ for spherical voids containing 339 vacancies in iron at $300 \mathrm{~K}$ with the same spacing as here [30], compared with $212 \mathrm{MPa}$ for 331-SIA loops at $300 \mathrm{~K}$ and $290 \mathrm{MPa}$ at $100 \mathrm{~K}$, as shown by the $\tau$ versus $\varepsilon$ plots in Fig. 8. Note that the edge dislocation shape at the critical stress $\tau_{c}$ is similar to that in the Orowan mechanism, i.e. a dipole of two parallel screw segments with spacing close to the obstacle size. The effective size for the 331-SIA loop is larger than that for the 339-vacancy void, namely $\sim 5 \mathrm{~nm}$ compared with $\sim 2 \mathrm{~nm}$. This is probably the main reason for the higher $\tau_{\mathrm{c}}$ value for the 331-SIA loop because $\tau_{\mathrm{c}}$ for the Orowan configuration scales roughly as the logarithm of the obstacle size [33]

As with small loops, all the interstitials are absorbed in the pair of glissile superjogs, except at $100 \mathrm{~K}$, so the process can be expected to be efficient at removing damage from slip bands. We have not investigated the size, which may be T- and $\underline{\text { s}}-$ dependent, for the transition from small-to-large loop behaviour. Extensive modelling is required and will be the subject of a later paper.

Only one line length $\mathrm{L}_{\mathrm{L}}$ (= loop separation) is treated here, but results have general applicability for the following reasons. For large loops, where the dislocation side arms bend to the screw orientation, i.e. the line shape is that of the Orowan process (strong

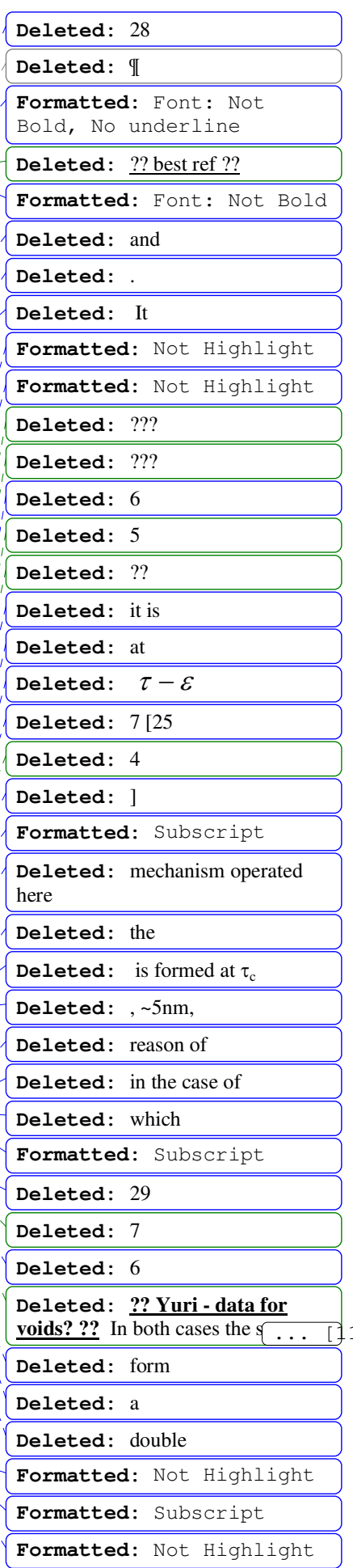


obstacles), the critical stress is found in continuum self-stress modelling [33] and MD/MS atomic-scale modelling of strengthening $[23,30,34]$ to be proportional to $\left(1 / \mathrm{L}_{\mathbb{N}}\right)$. For small loops that are absorbed by the dislocation, the stress is again proportional to $\left(1 / \mathrm{L}_{\mathrm{y}}\right)$ because the critical step (vacancy creation at the jog) is a localised process. Simple estimates of the stress $\tau_{c}$ required for the length $\mathrm{L}_{\mathrm{W}}$ to move forward and do work $\left(\approx \tau_{\mathrm{d}} \mathrm{b}^{2} \mathrm{~L}_{\mathrm{k}}\right)$ to create a vacancy confirm this.

In very recent work, Nomoto et al. [20] have reported MD simulation of the interaction of an edge dislocation with a periodic row of 99-SIA loops in iron with the same Burgers vector orientations as used here. The model size was only a little smaller than the one used here - $\mathrm{L}_{\mathrm{y}}$ was $35 \mathrm{~nm}$ compared with $41 \mathrm{~nm}$ - and the interatomic potential was the same. The temperature was not given in the paper. The final configuration found after the dislocation had reacted with the loop was the same as found here, viz. glissile superjogs and a few vacancies. However, the transformation mechanism described in [16] is different, for the $<100>$ dislocation ('bridge') formed initially was observed to split into two $1 / 2<111>$ segments that slipped down on the inclined $\{110\}$ plane. (For the orientation used here in Fig. 1, the equivalent process on the (101) plane would be $[010]=1 / 2[11 \overline{1}]+$ $1 / 2[\overline{1} 11]$.) The difference may be due to the different loop size considered or, more likely, the way the crystal was loaded. The model in [20] was deformed by applying a constant shear stress rather than a constant strain rate. At $\tau=50 \mathrm{MPa}$, the dislocation was stopped by the loop and so stress in the range 150 to $650 \mathrm{MPa}$ was simulated for loop transformation and absorption. Under these high stress (and therefore high strain rate) conditions, the free-flight velocity of the edge dislocation is in excess of $1000 \mathrm{~ms}^{-1}[18,19]$, compared with $\sim 12 \mathrm{~ms}^{-1}$ at, say, ś $=5 \times 10^{6} \mathrm{~s}^{-1}$ in the present work. Thus, the complete process took a few tens of ps in [20], compared with times one to two orders of magnitude longer for the much lower strain rates used here. The process simulated in [20] is strongly affected by kinetic effects such as observed elsewhere for high dislocation velocities [34.35]. Hence, it is not straightforward to compare the atomic mechanisms. Furthermore, critical stress values were not obtained by the procedure used in [20].

Finally, it should be emphasised again that, irrespective of the size of the interacting loop, complete absorption of the interstitials occurs by all but one of the interactions found here. In addition to removing damage from the crystal by this process, the superjogs on the gliding dislocation increase the possibility of dislocation interaction 
with other defects. This may enhance absorption of other SIAs or annihilation of vacancy defects. Investigation of this, and analysis of the drag effect such jogs have on slip, will be the subjects of a future paper.

\section{Conclusions}

(a) Perfect dislocation loops containing from a few tens to hundreds of self-interstitial atoms in iron lying within a few tens of $\mathrm{nm}$ of the slip plane of an edge dislocation can glide to react with the dislocation when the loop Burgers vector, $\boldsymbol{b}$, is inclined to the slip plane.

(b) The Burgers vector of small loops (37 SIAs here) changes spontaneously on contact and the interstitials are absorbed as a pair of superjogs. The line glides forward at critical stress $\tau_{c}$ when one or more vacancies are created and the jogs adopt glissile form.

(c) $\tau_{\mathrm{c}}$ is $51 \mathrm{MPa}$ at $\mathrm{T}=0 \mathrm{~K}$ and lies between 13 and $27 \mathrm{MPa}$ for $100 \leq \mathrm{T} \leq 450 \mathrm{~K}$. These loops are weaker obstacles than voids with a similar number of vacancies.

(d) A large loop (331 SIAs here) reacts spontaneously with the dislocation to form a segment with $\boldsymbol{b}=\langle 100\rangle$, which is sessile on the dislocation slip plane, and as $\tau$ increases the dislocation side arms are pulled into screw orientation. The $\langle 100\rangle$ segment is glissile on an inclined $\{110\}$ plane at 300 and $450 \mathrm{~K}$, and glides across the loop as the side arms cross-slip, thereby transforming the loop into a pair of superjogs, which, as in (b), becomes glissile at $\tau_{c}$. The $<100>$ segment is immobile at $100 \mathrm{~K}$, however, and the dislocation breaks away from the loop by cross-slip and mutual annihilation of its screw side arms.

(e) $\tau_{\mathrm{c}}$ lies between 290 and $160 \mathrm{MPa}$ for $100 \leq \mathrm{T} \leq 450 \mathrm{~K}$. These loops are stronger obstacles than voids with a similar number of vacancies because of the larger effective size of loops.

(f) With the exception of the large loop at low temperature, the interaction process is efficient for absorption of SIA clusters from slip bands, as observed in flow localisation,

Formatted: Bullets and Numbering

Deleted: but

Deleted: . As $\tau$ increases and the dislocation side arms are pulled into screw orientation, the segment

Deleted: and

Deleted: $s$ it

Deleted: 250 Deleted: ?? Deleted: ? - not finished yet. Current stress is $\sim 200$ at $\varepsilon \sim 1$ ?))

Deleted: Irrespective of size

Deleted: $n$ 


\section{ACKNOWLEDGEMENTS}

This research was sponsored by (i) grant PERFECT (F160-CT-2003-508840) under programme EURATOM FP-6 of the European Commission, (ii) a research grant from the UK Engineering and Physical Sciences Research Council and (iii) the Division of Materials Sciences and Engineering and the Office of Fusion Energy Sciences, U.S. Department of Energy, under contract DE-AC05-00OR22725 with UT-Battelle, LLC. 


\section{References}

1. D.J. Bacon, F. Gao and Yu.N. Osetsky, J. Nucl. Mater. 2761 (2000).

2. Yu.N. Osetsky, D.J. Bacon, A. Serra, B.N. Singh and S.I. Golubov, Phil. Mag. A 83 61 (2003).

3. B.D. Wirth, G.R. Odette, D. Maroudas and G.E. Lucas, J. Nucl. Mater. 244185 (1997); ibid. 27633 (2000).

4. Yu.N. Osetsky, D.J. Bacon, A. Serra, B.N. Singh and S.I. Golubov, J. Nucl. Mater. 27665 (2000)

5. N. Soneda and T. Diaz de la Rubia, Phil. Mag. A 81 331(2001),

6. B. N. Singh, A. Horsewell, P. Toft, D.J. Edwards, J. Nucl. Mater. 224.131 (1995).

7. Yu.N. Osetsky, D.J. Bacon, F. Gao, A. Serra and B.N. Singh, J. Nucl. Mater. 283-287 $784(2000)$.

8. NM. Ghoniem, S. H. Tong, J. Huang, B,N. Singh and M. Wen, J. Nucl. Mater. 307- * 311843 (2002).

9. M. Victoria, N. Baluc, C. Bailat, Y. Dai, M.I. Luppo, R. Schaublin and B.N. Singh, J . Nucl. Mater. 276114 (2000).

10. B.N. Singh, H. Trinkaus, and A.J.E. Foreman, J. Nucl. Mater,249,91 (1997); ibid. 251, 172 (1997).

11. N.M. Ghoniem, S.H. Tong, B.N. Singh and L.Z. Sun, Phil. Mag. 812743 (2001).

12. Z. Rong, V. Mohles, D.J. Bacon and Yu.N. Osetsky, Phil. Mag. 85171 (2005).

13. M.J. Makin, Phil Mag. 10695 (1964).

14. B.L. Eyre and R. Bullough, Phil. Mag. 12.31,(1965).

15. J. Marian, B.D. Wirth and J.M. Perlado, Phys. Rev. Lett. 88 255507-1 (2002).

16. J. Marian, B.D. Wirth, R. Schäublin, G.R. Odette and J.M Perlado, J. Nucl. Mater. 323 181 (2003).

17. S. Jumel, J-C. Van Duysen, J Ruste and C. Domain, J. Nucl. Mater. 34679 (2005).

18. Yu.N. Osetsky, D.J. Bacon, Z. Rong and B.N. Singh, Phil. Mag. Lett. 84745 (2004). *

19. Z. Rong, Yu.N. Osetsky and D.J. Bacon, Phil. Mag. 851473 (2005).

20. A. Nomoto, N. Soneda, A. Takahashi and S. Ishino, Mats. Trans. 46463 (2005).

21. D. Rodney and G. Martin, Phys. Rev. Lett. 823273 (1999).

22. D. Rodney and G. Martin, Phys. Rev. B 718714 (2000). 
23. Yu.N. Osetsky and D.J.Bacon, Modelling Simul. Mat. Sci. Eng. 11427 (2003).

24. G.J. Ackland, D.J. Bacon, A.F. Calder and T. Harry, Phil. Mag. A 75713 (1997).

25. B.N. Singh, A. Horsewell and P. Toft, J. Nucl, Mater 271-272 77 (1999).

26. M.I. Luppo, C. Bailat, R. Schäublin and M. Victoria, J. Nucl. Mater. 283-287 483 (2000).

27. S.J. Zinkle and B.N. Singh, J. Nucl, Mater (2005), in press,

28. Yu.N. Osetsky, A. Serra and V. Priego, J. Nucl. Mater. 276202 (2000).

29. D. Hull and D.J. Bacon, Introduction to Dislocations, $4^{\text {th }}$ edition, ButterworthHeinemann, 2001.

30. Yu.N. Osetsky and D.J. Bacon, J. Nucl. Mater. 323, 268 (2003).

31. D.J. Bacon, Yu.N. Osetsky and Z. Rong, unpublished work.

32. F. Gao, H. Heinisch, R.J. Kurtz, Yu.N. Osetsky, R.G. Hoagland, Phil. Mag. 85619 (2005).

33. D.J. Bacon, U.F. Kocks and R.O. Scattergood, Phil,Mag 26 1242 (1973).

34. Y.N. Osetsky and D.J. Bacon, J. Nucl. Mater 323268 (2003).

35. E. Bitzek and P. Gumbsch, Mat. Sci. and Eng. A 387-389 11 (2004). 


\section{Figure captions}

Fig. 1. Schematic illustration of the edge dislocation and SIA loop in one periodic cell. The sense of positive applied stress resolved shear stress, $\tau$, is indicated by the block arrows.

Fig. 2. Visualisations of the spontaneous glide and absorption process of a 37-SIA loop on the edge dislocation at $\mathrm{T}=0 \mathrm{~K}$. The value of applied strain, $\varepsilon$, corresponding to the abscissa of Fig. 3 is indicated.

Fig. 3. $\tau$ versus $\varepsilon$ plots for the glide and absorption process for a 37-SIA loop. The ${ }^{+}$ molecular statics (MS) simulations for $\mathrm{T}=0 \mathrm{~K}$ are for $\Delta \varepsilon$ increments of either 2 or $10 \times 10^{-5}$. The MD simulation is for $\mathrm{T}=100 \mathrm{~K}$ and $\dot{s}=2 \times 10^{6} \mathrm{~s}^{-1}$.

Fig. 4. $\tau_{\mathrm{c}}$ versus $\mathrm{T}$ for 37-SIA and 331-SIA loops at various values of $\dot{s}$ in units $10^{6} \mathrm{~s}^{-1}$. The MS $(\mathrm{T}=0 \mathrm{~K})$ value for the small loop is the maximum on the MS plots in Fig. 3.

Fig. 5. Visualisations of the spontaneous glide and transformation process of a 331-SIA loop at $\mathrm{T}=300 \mathrm{~K}$ and $\dot{\boldsymbol{s}}=20 \times 10^{6} \mathrm{~s}^{-1}$. The [010] segment has formed in (b) and is seen to glide down as the dislocation side arms in screw orientation glide down in (c) and (d).

Fig. 6. Schematic illustration of the processes observed in Fig. 5. The line arrows and index arrows show the positive line direction and Burgers vector as given by the RH/FS convention.

Fig. 7. Visualisations of the interaction process for a 331-SIA loop at $\mathrm{T}=100 \mathrm{~K}$ and $\delta$ $5 \times 10^{6} \mathrm{~s}^{-1}$. The [010] segment has formed in (a) and two dislocation side arms in screw orientation have been drawn out and started to cross-slip towards each other in (b).

Fig. 8. $\tau$ versus $\varepsilon$ plots for a 331-SIA loop at two temperatures and a 339-vacancy void for $=5 \times 10^{6} \mathrm{~s}^{-1}$ at $\mathrm{T}=300 \mathrm{~K}$.

Formatted: Justified, Line spacing: 1.5 lines

Deleted: for

Deleted: $\boldsymbol{\varepsilon}$

Formatted: Line spacing: 1.5 lines

Deleted: 5

Formatted: Not Highlight

Formatted: Not Highlight

Field Code Changed

Formatted: Line spacing: 1.5 lines

Deleted: 7

Deleted:

Deleted: $\mathrm{T}$

Deleted: $r$

Deleted: $\dot{\varepsilon}$

Formatted: Font: $12 \mathrm{pt}$, Complex Script Font: 12

Deleted: II

Formatted: Font: $12 \mathrm{pt}$ Complex Script Font: 12

Deleted: II
II
II
II
II
II
II
II
II
II
II
II
Fig.7
Formatted: Justified,
Indent: Before: 0 pt,
Hanging: 42.55 pt, Line
Spacing: 5 ines


Page 6: [1] Formatted

David Bacon

1/10/2006 1:27:00 PM

Font: 12 pt, Complex Script Font: 12 pt

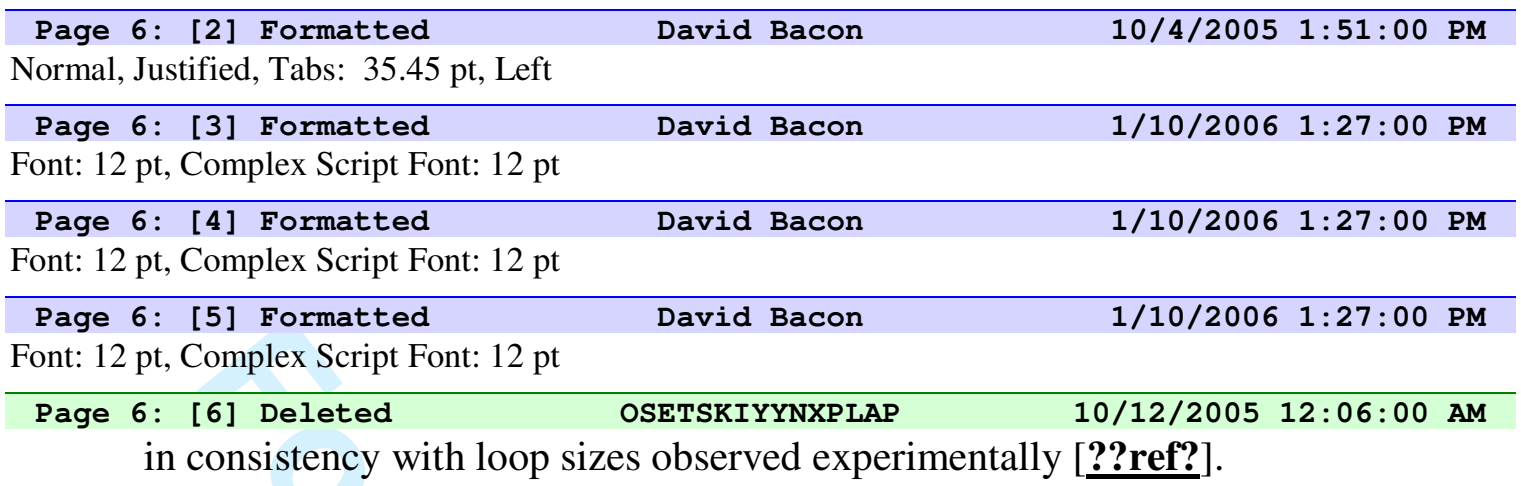

Page 6: [7] Formatted

David Bacon

1/10/2006 1:27:00 PM

Font: 12 pt, Complex Script Font: 12 pt

Page 6: [8] Formatted David Bacon $\quad 1 / 10 / 2006$ 1:27:00 PM

Font: 12 pt, Complex Script Font: 12 pt

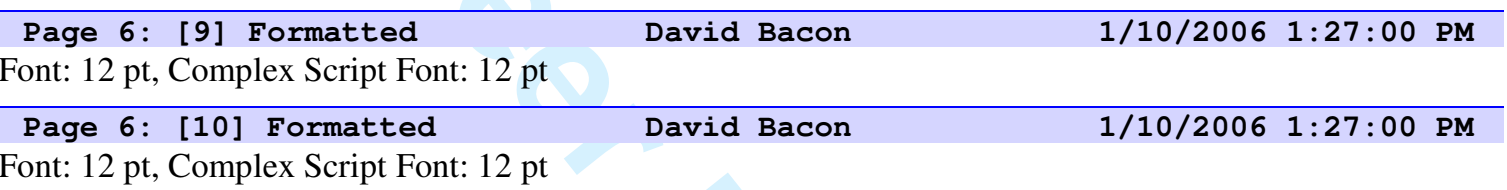

Page 9: [11] Deleted OSETSKIYYNXPLAP 10/12/2005 12:23:00 AM

?? Yuri - data for voids? ?? In both cases the screw dipole configuration is

achieved at $\tau_{c}$, but the size, i.e. diameter, is larger for a loop and so $\tau_{c}$, which scales roughly as the logarithm of size for voids and, presumably loops, is also larger

\begin{tabular}{lll}
\hline Page 10: [12] Formatted & David Bacon & $1 / 10 / 2006$ 1:27:00 PM \\
Subscript, Not Highlight &
\end{tabular}

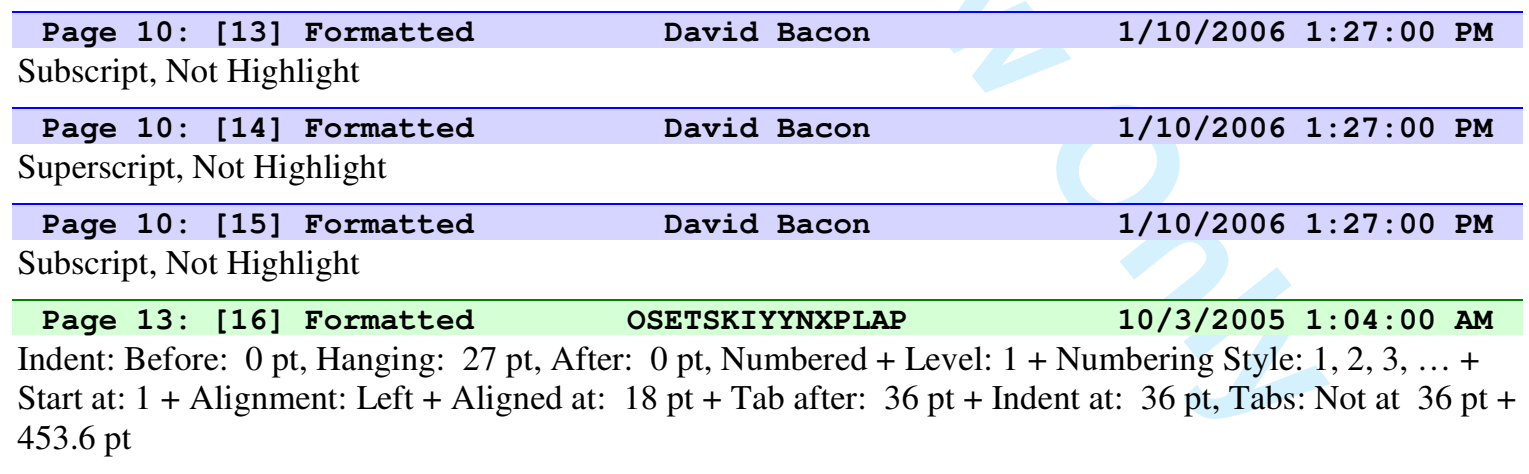

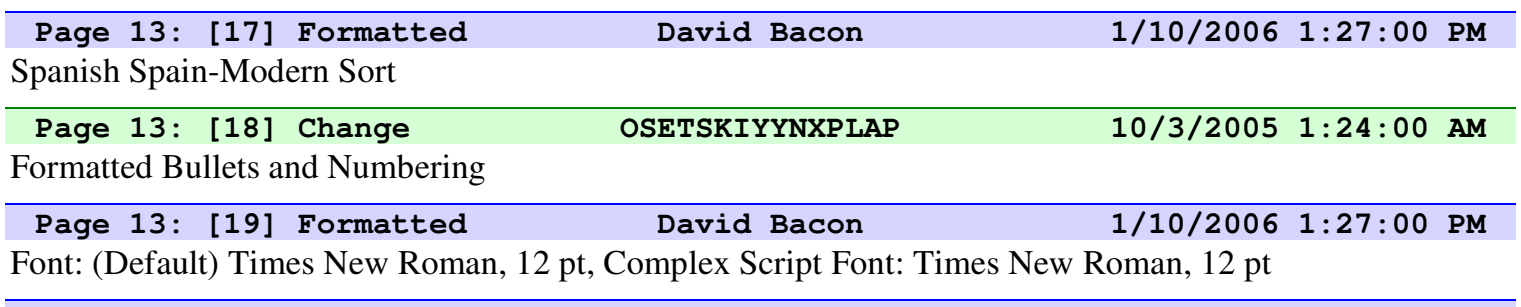

\footnotetext{
Page 13: [19] Formatted David Bacon 1/10/2006 1:27:00 PM
}

Font: (Default) Times New Roman, 12 pt, Complex Script Font: Times New Roman, 12 pt 
Page 13: [19] Formatted

David Bacon

1/10/2006 1:27:00 PM

Font: (Default) Times New Roman, 12 pt, Bold, Complex Script Font: Times New Roman, 12 pt

Page 13: [19] Formatted David Bacon 1/10/2006 1:27:00 PM

Font: (Default) Times New Roman, 12 pt, Complex Script Font: Times New Roman, 12 pt

Page 13: [19] Formatted David Bacon
Font: Not Bold

Page 13: [19] Formatted David Bacon $1 / 10 / 2006$ 1:27:00 PM

Font: (Default) Times New Roman, 12 pt, Complex Script Font: Times New Roman, 12 pt

Page 13: [20] Formatted OSETSKIYYNXPLAP 10/3/2005 1:24:00 AM

Indent: Before: 0 pt, Hanging: 27 pt, Line spacing: 1.5 lines, Numbered + Level: $1+$ Numbering Style: 1 , $2,3, \ldots+$ Start at: $1+$ Alignment: Left + Aligned at: $18 \mathrm{pt}+$ Tab after: $36 \mathrm{pt}+$ Indent at: $36 \mathrm{pt}$, Tabs: Not at $18 \mathrm{pt}+36 \mathrm{pt}$

\begin{tabular}{|c|c|c|}
\hline Page 13: [21] Formatted & David Bacon & $1 / 10 / 2006 \quad 1: 27: 00 \mathrm{PM}$ \\
\hline \multicolumn{3}{|c|}{ Font: 12 pt, Complex Script Font: 12 pt } \\
\hline Page 13: [22] Change & OSETSKIYYNXPLAP & $10 / 13 / 200512: 07: 00 \mathrm{AM}$ \\
\hline \multicolumn{3}{|l|}{ Formatted Bullets and Numbering } \\
\hline Page 13: [23] Deleted & David Bacon & $10 / 12 / 20057: 43: 00 \mathrm{PM}$ \\
\hline Page 13: [23] Deleted & David Bacon & $10 / 12 / 20057: 43: 00 \mathrm{PM}$ \\
\hline
\end{tabular}

\begin{tabular}{|c|c|c|}
\hline Page 13: [24] Formatted & David Bacon & $1 / 10 / 2006 \quad 1: 27: 00 \mathrm{PM}$ \\
\hline
\end{tabular}

\begin{tabular}{|c|c|c|}
\hline Page 13: [24] Formatted & David Bacon & $1 / 10 / 2006 \quad 1: 27: 00 \mathrm{PM}$ \\
\hline \multicolumn{3}{|c|}{ Font: 12 pt, Complex Script Font: 12 pt } \\
\hline Page 13: [24] Formatted & David Bacon & $1 / 10 / 2006 \quad 1: 27: 00 \mathrm{PM}$ \\
\hline \multicolumn{3}{|l|}{ English U.S. } \\
\hline Page 13: [25] Formatted & David Bacon & $1 / 10 / 2006 \quad 1: 27: 00 \mathrm{PM}$ \\
\hline
\end{tabular}

Page 13: [26] Formatted OSETSKIYYNXPLAP $10 / 3 / 2005$ 1:24:00 AM

Indent: Before: 0 pt, Hanging: 27 pt, Line spacing: 1.5 lines, Numbered + Level: $1+$ Numbering Style: 1 , $2,3, \ldots+$ Start at: $1+$ Alignment: Left + Aligned at: $18 \mathrm{pt}+$ Tab after: $36 \mathrm{pt}+$ Indent at: $36 \mathrm{pt}$, Tabs: Not at $18 \mathrm{pt}+36 \mathrm{pt}$

Page 13: [27] Formatted David Bacon 1/10/2006 1:27:00 PM

Font: (Default) Times New Roman, 12 pt, Complex Script Font: Times New Roman, 12 pt

Page 13: [27] Formatted David Bacon 1/10/2006 1:27:00 PM

Font: (Default) Times New Roman, 12 pt, Complex Script Font: Times New Roman, 12 pt

\begin{tabular}{cccc}
\hline Page 13: [28] Formatted & David Bacon & 1/10/2006 1:27:00 PM \\
Font: (Default) Times New Roman, 12 pt, Complex Script Font: Times New Roman, 12 pt
\end{tabular}

Font: (Default) Times New Roman, 12 pt, Complex Script Font: Times New Roman, 12 pt

Page 13: [28] Formatted David Bacon 1/10/2006 1:27:00 PM

Font: (Default) Times New Roman, 12 pt, Complex Script Font: Times New Roman, 12 pt

Page 13: [28] Formatted David Bacon 1/10/2006 1:27:00 PM

Font: (Default) Times New Roman, 12 pt, Complex Script Font: Times New Roman, 12 pt

Page 13: [28] Formatted David Bacon 1/10/2006 1:27:00 PM

Font: (Default) Times New Roman, 12 pt, Complex Script Font: Times New Roman, 12 pt

Page 13: [28] Formatted David Bacon 1/10/2006 1:27:00 PM

Font: (Default) Times New Roman, 12 pt, Not Italic, Complex Script Font: Times New Roman, 12 pt 
Font: (Default) Times New Roman, 12 pt, Complex Script Font: Times New Roman, 12 pt
Page 13: [30] Formatted
David Bacon
$1 / 10 / 20061: 27: 00 \mathrm{PM}$

Font: (Default) Times New Roman, 12 pt, Complex Script Font: Times New Roman, 12 pt

Page 13: [30] Formatted David Bacon 1/10/2006 1:27:00 PM

Font: (Default) Times New Roman, 12 pt, Complex Script Font: Times New Roman, 12 pt

Page 13: [30] Formatted David Bacon 1/10/2006 1:27:00 PM

Font: (Default) Times New Roman, 12 pt, Complex Script Font: Times New Roman, 12 pt

Page 13: [30] Formatted David Bacon 1/10/2006 1:27:00 PM

English U.S.
Page 13: [31] Deleted
OSETSKIYYNXPLAP
10/3/2005 1:30:00 AM
B.N. Singh, A.J.E. Foreman and H. Trinkaus, J. Nucl. Mater. 249 103(1997).
H. Trinkaus, B.N. Singh and A.J.E. Foreman, J. Nucl. Mater. 24991 (1997).

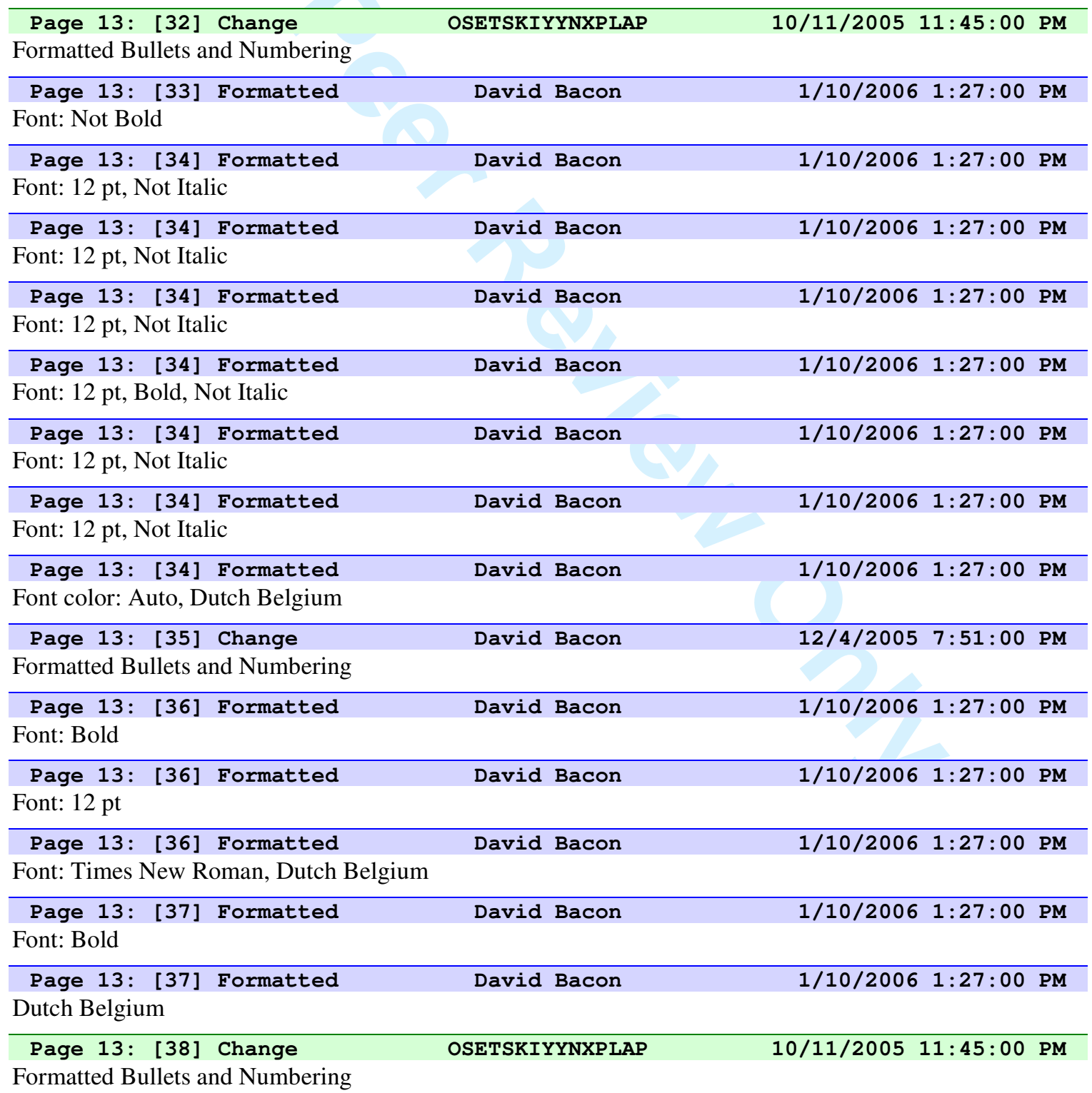


Page 14: [39] Formatted David Bacon

1/10/2006 1:27:00 PM

Font: 12 pt, Complex Script Font: 12 pt

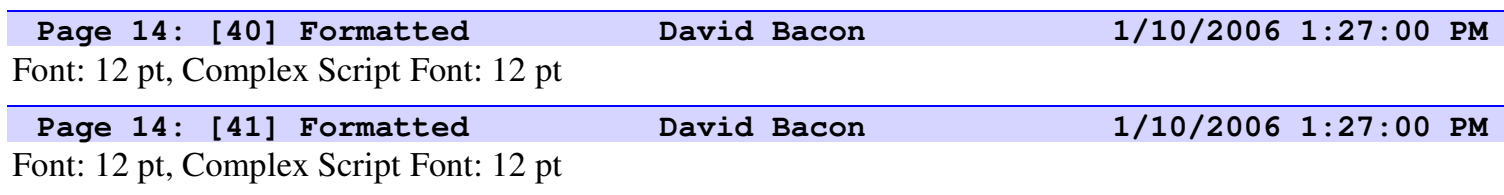

Page 14: [42] Formatted David Bacon $1 / 10 / 2006$ 1:27:00 PM

Font: 12 pt, Complex Script Font: 12 pt

Page 14: [43] Formatted David Bacon

$1 / 10 / 20061: 27: 00 \mathrm{PM}$

Font: 12 pt, Bold, No underline, Complex Script Font: 12 pt

Page 14: [44] Formatted David Bacon 1/10/2006 1:27:00 PM

Font: 12 pt, Bold, Complex Script Font: 12 pt

Page 14: [45] Formatted David Bacon $1 / 10 / 2006$ 1:27:00 PM

Font: 12 pt, Bold, No underline, Complex Script Font: 12 pt

Page 14: [46] Formatted David Bacon 1/10/2006 1:27:00 PM

Font: 12 pt, Complex Script Font: 12 pt

Page 14: [47] Deleted David Bacon $\quad 10 / 12 / 2005$ 7:44:00 PM

M.I. Luppo, C. Bailat, R. Schäublin and M.Victoria, J.Nucl. Mater., 283-287 483 (2000).

\begin{tabular}{|c|c|c|}
\hline Page 14: [48] Formatted & David Bacon & $1 / 10 / 2006 \quad 1: 27: 00 \mathrm{PM}$ \\
\hline Font: $12 \mathrm{pt}$, Complex Script Font: $12 \mathrm{pt}$ & & \\
\hline Page 14: [49] Formatted & David Bacon & $1 / 10 / 2006 \quad 1: 27: 00 \mathrm{PM}$ \\
\hline
\end{tabular}

Page 14: [50] Formatted David Bacon 10/12/2005 7:44:00 PM

Indent: Before: 0 pt, Hanging: 28.35 pt, Numbered + Level: $1+$ Numbering Style: $1,2,3, \ldots+$ Start at: 1

+ Alignment: Left + Aligned at: $18 \mathrm{pt}+$ Tab after: $36 \mathrm{pt}+$ Indent at: $36 \mathrm{pt}$, Tabs: $28.35 \mathrm{pt}$, List tab + Not at $36 \mathrm{pt}$

Page 14: [51] Formatted

Font: 12 pt, Complex Script Font: 12 pt

\begin{tabular}{|c|c|c|}
\hline Page 14: [52] Formatted & David Bacon & $1 / 10 / 2006 \quad 1: 27: 00 \mathrm{PN}$ \\
\hline Font: $12 \mathrm{pt}$, Complex Script Font: $12 \mathrm{pt}$ & & \\
\hline
\end{tabular}

Font: 12 pt, Bold, No underline, Complex Script Font: 12 pt

Page 14: [54] Formatted David Bacon 1/10/2006 1:27:00 PM

Font: $12 \mathrm{pt}$, Bold, Complex Script Font: $12 \mathrm{pt}$

\begin{tabular}{lcc}
\hline Page 14: [55] Formatted & David Bacon & $1 / 10 / 2006$ 1:27:00 PM \\
Font: $12 \mathrm{pt}$, Bold, No underline, Complex Script Font: $12 \mathrm{pt}$ & \\
\hline
\end{tabular}

Page 14: [56] Formatted 1 David Bacon
Font: $12 \mathrm{pt}$, Bold, Complex Script Font: $12 \mathrm{pt}$

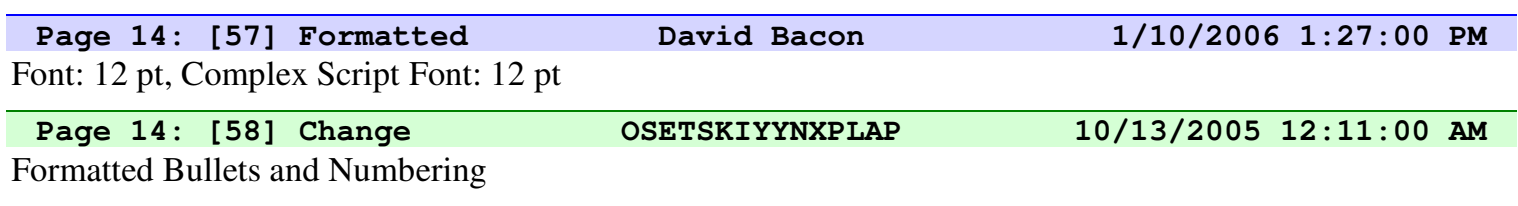

Page 14: [59] Change David Bacon 10/12/2005 7:46:00 PM

Formatted Bullets and Numbering

Page 14: [60] Formatted David Bacon 1/10/2006 1:27:00 PM 
Font: $12 \mathrm{pt}$, Complex Script Font: $12 \mathrm{pt}$

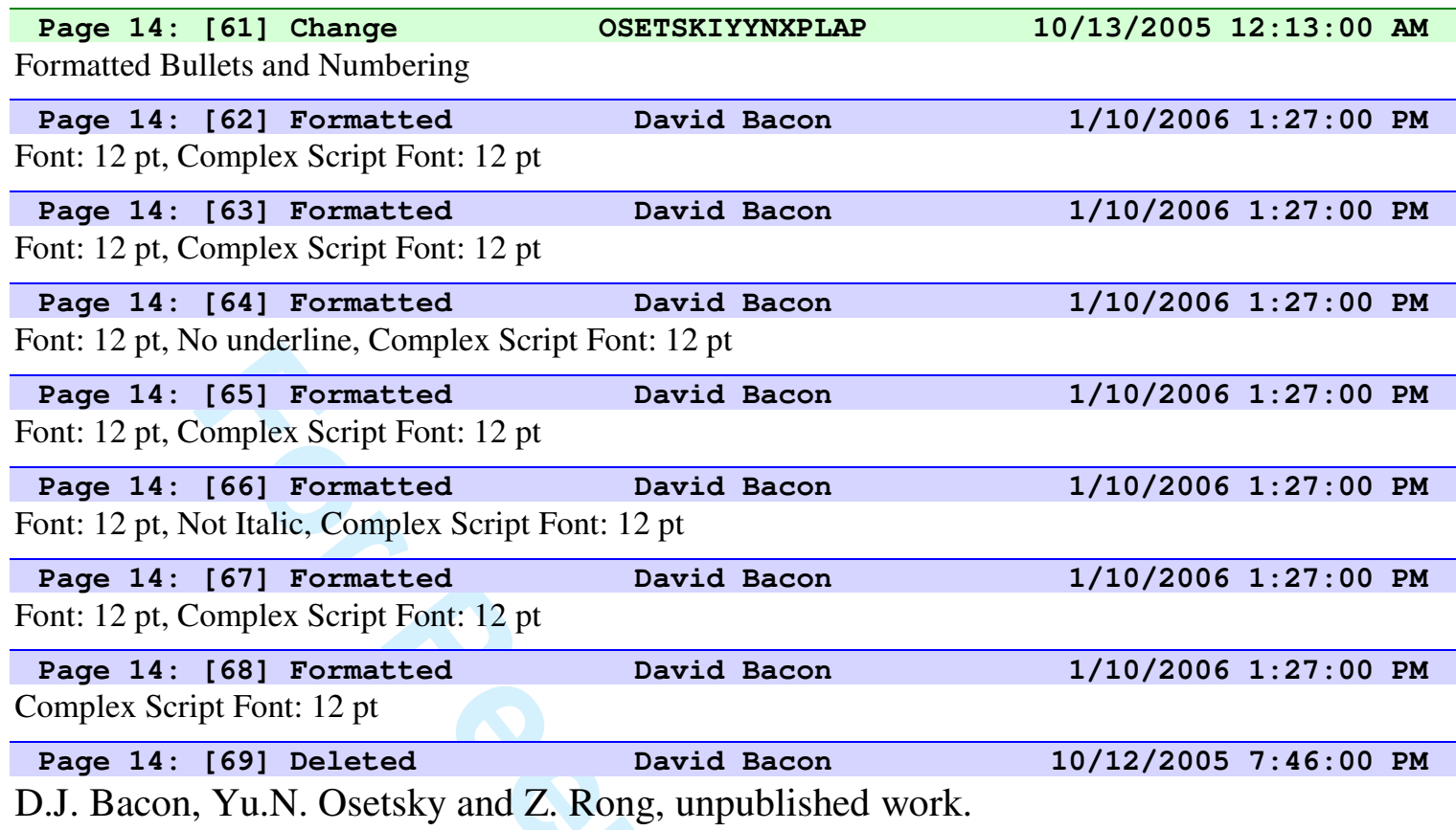

Yu.N. Osetsky and D.J. Bacon, unpublished work.

DAVID _ I did not find references to the two last papers?

Page 14: [70] Formatted David Bacon
Line spacing: 1.5 lines




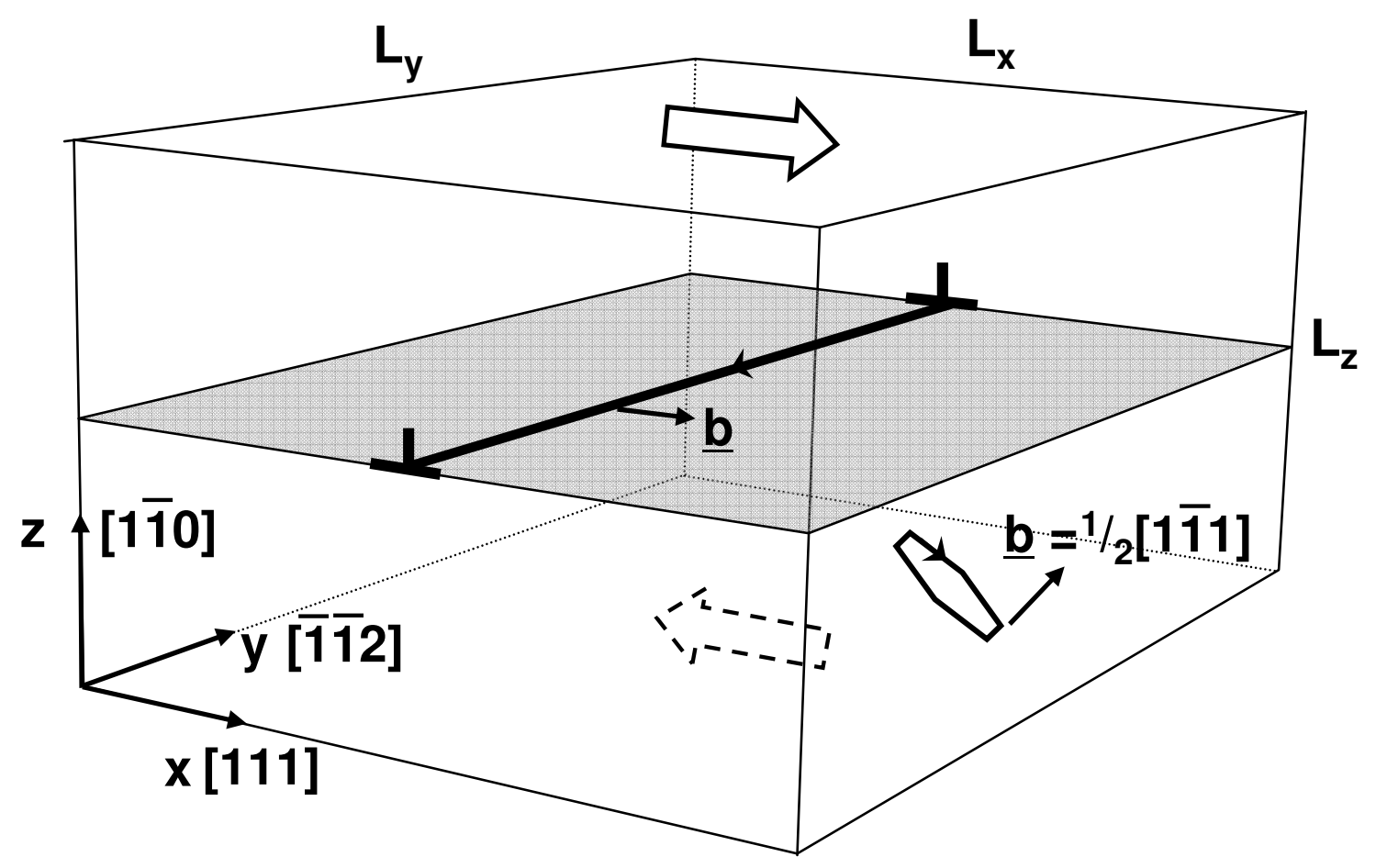




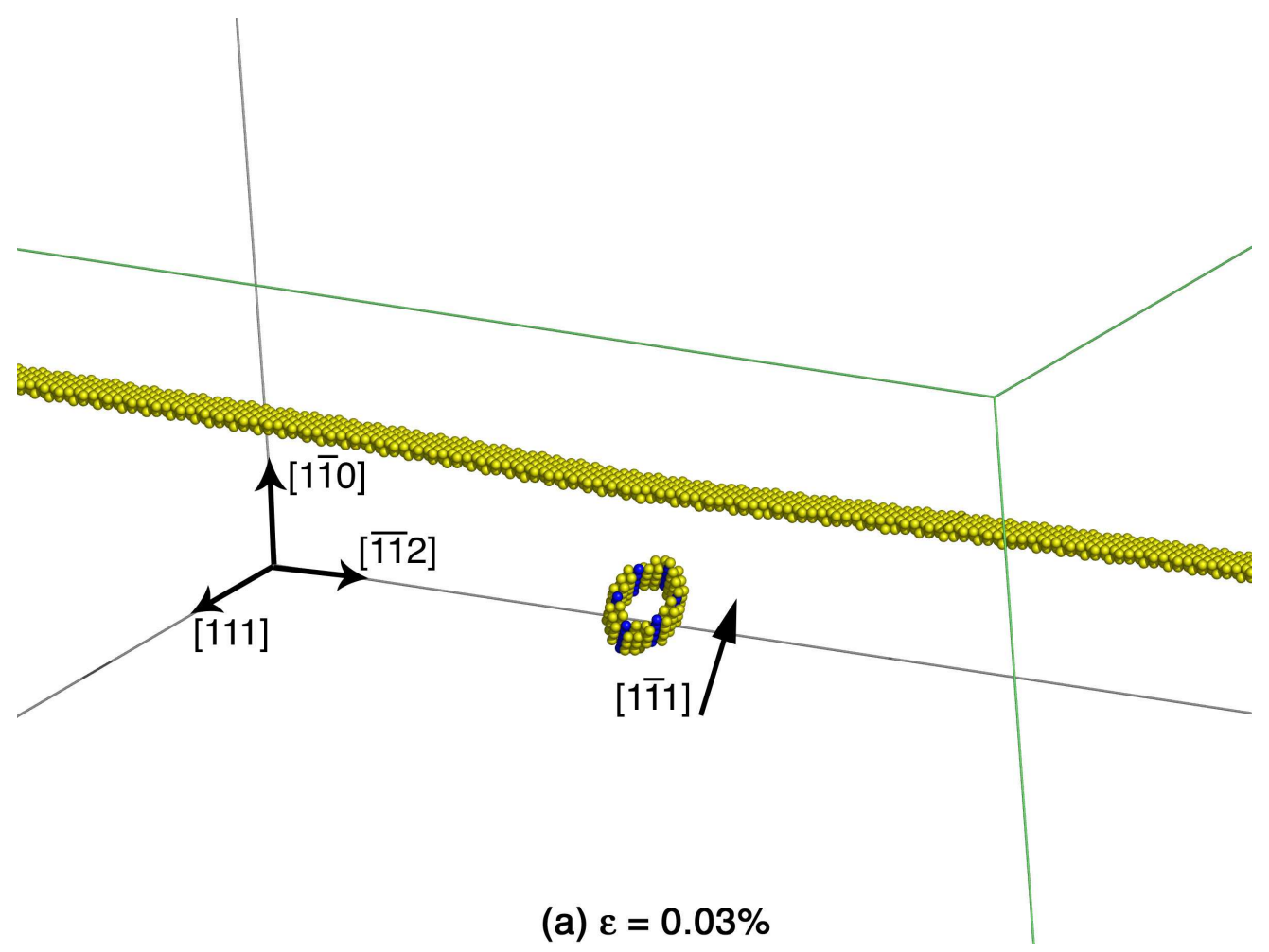

Figure $2 \mathrm{a}$

$846 \times 635 \mathrm{~mm}(72 \times 72 \mathrm{DPI})$ 


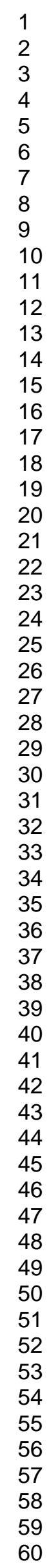

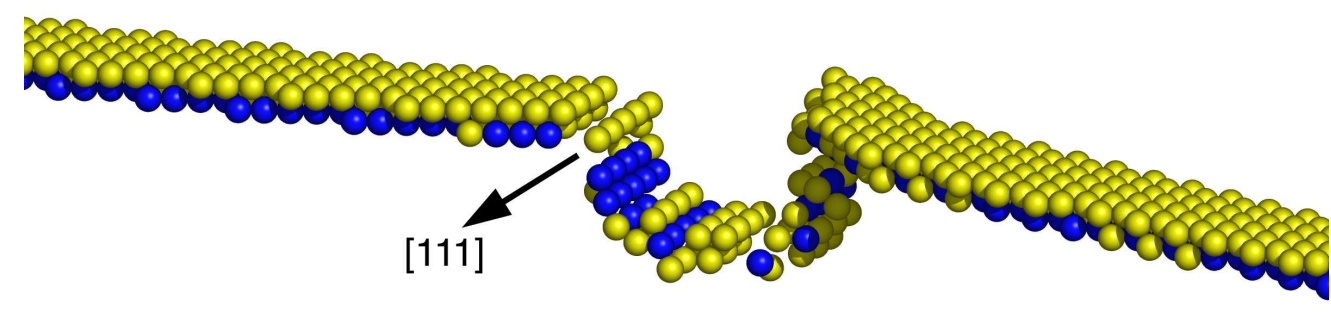

(b) $\varepsilon=0.214 \%$

Figure $2 b$

$846 \times 635 \mathrm{~mm}(72 \times 72$ DPI $)$

http://mc.manuscriptcentral.com/pm-pml 


1
2
3
4
5
6
7
8
9
10
11
12
13
14
15
16
17
18
19
20
21
22
23
24
25
26
27
28
29
30
31
32
33
34
35
36
37
38
39
40
41
42
43
44
45
46
47
48
49
50
51
52
53
54
55
56
57
59
60

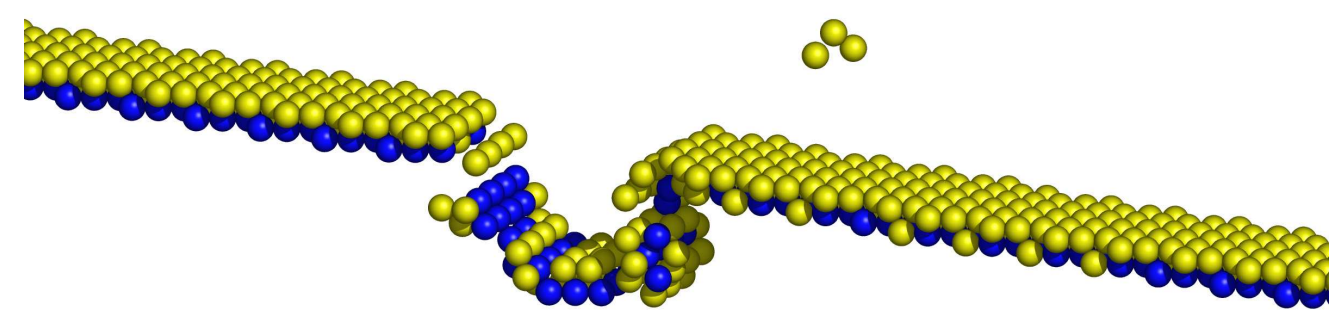

(c) $\varepsilon=0.234 \%$

Figure 2c

$846 \times 635 \mathrm{~mm}(72 \times 72 \mathrm{DPI})$ 


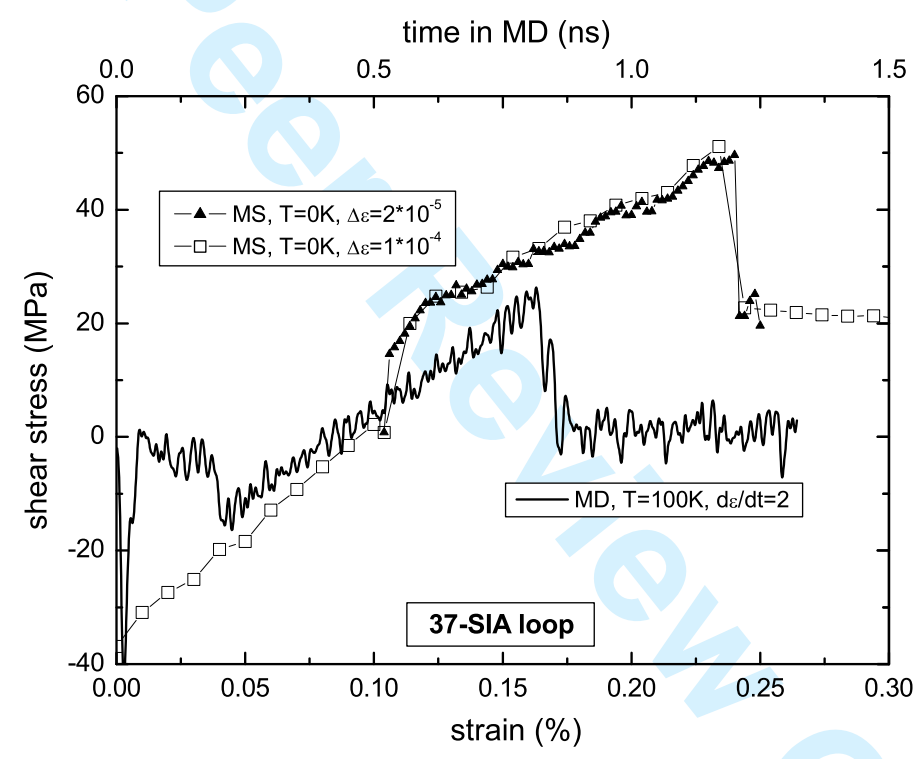




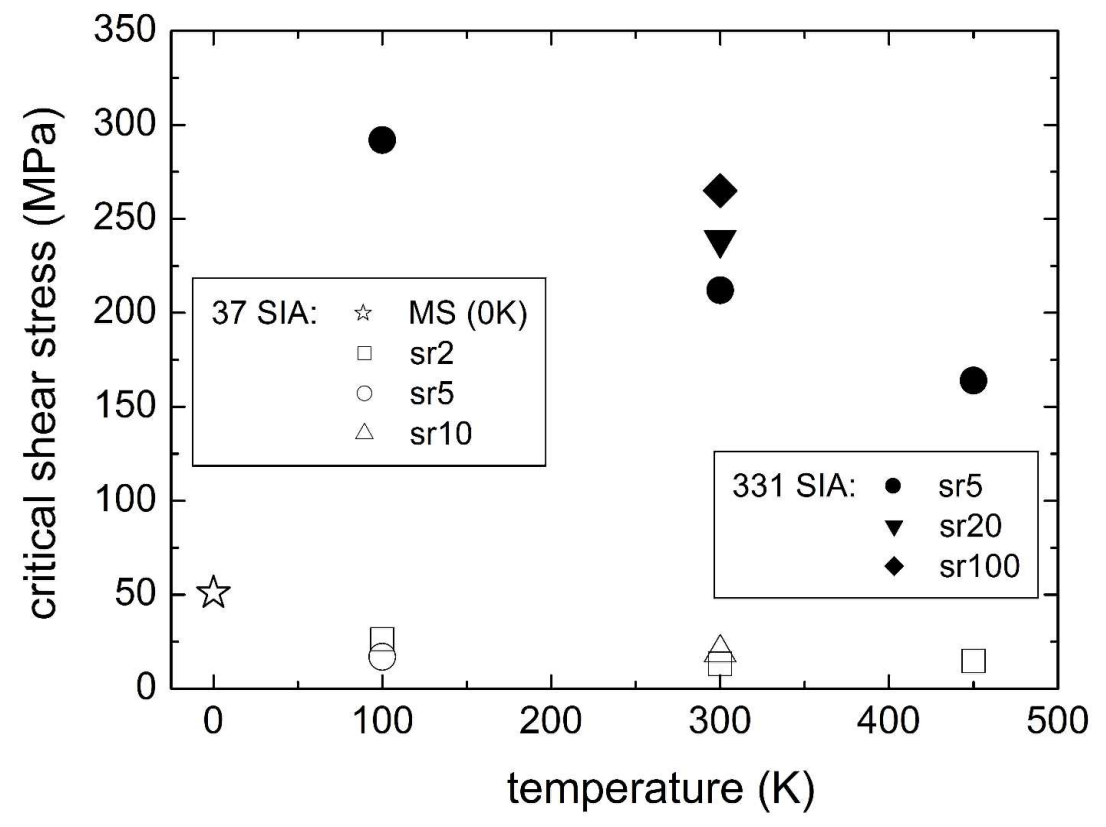

Figure 4

$352 \times 245 \mathrm{~mm}(489 \times 489$ DPI $)$ 


1
2
3
4
5
6
7
8
9
10
11
12
13
14
15
16
17
18
19
20
21
22
23
24
25
26
27
28
29
30
31
32
33
34
35
36
37
38
39
40
41
42
43
40
45
49
50
51
52
53
55
50

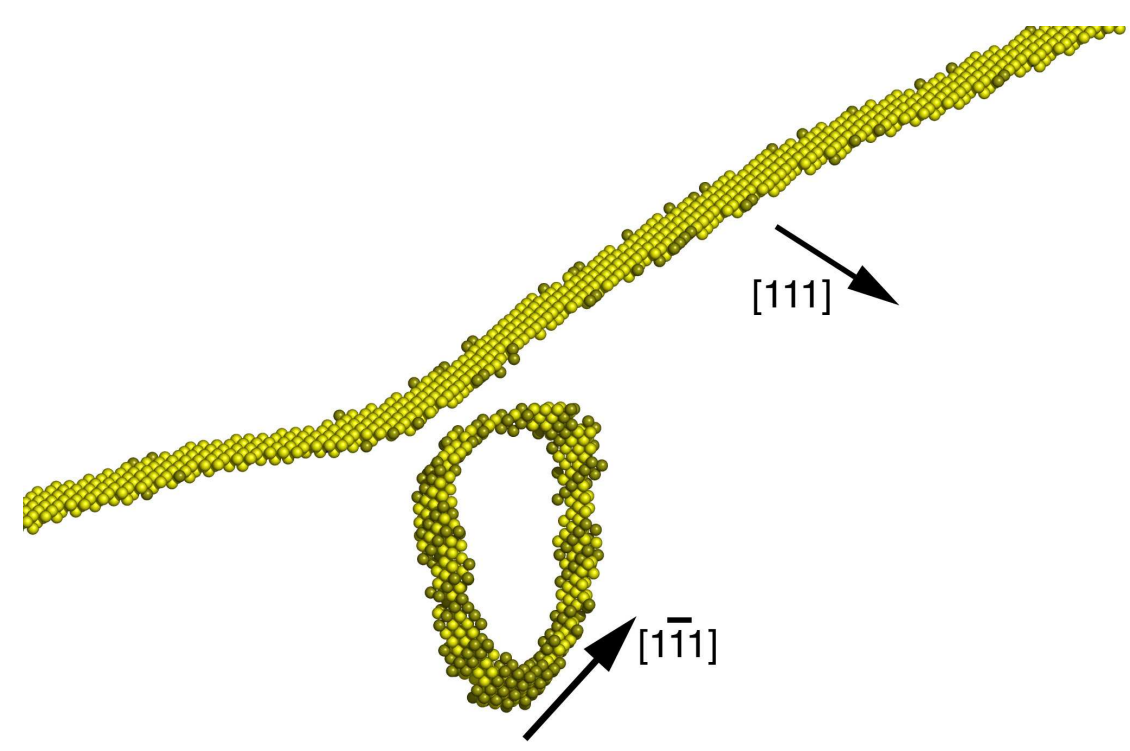

(a) $t=50 p s$

Figure $5 a$ $846 \times 635 \mathrm{~mm}(72 \times 72 \mathrm{DPI})$ 


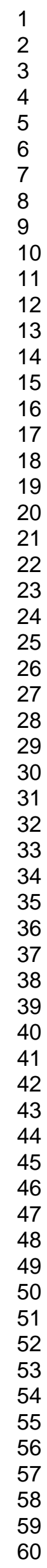

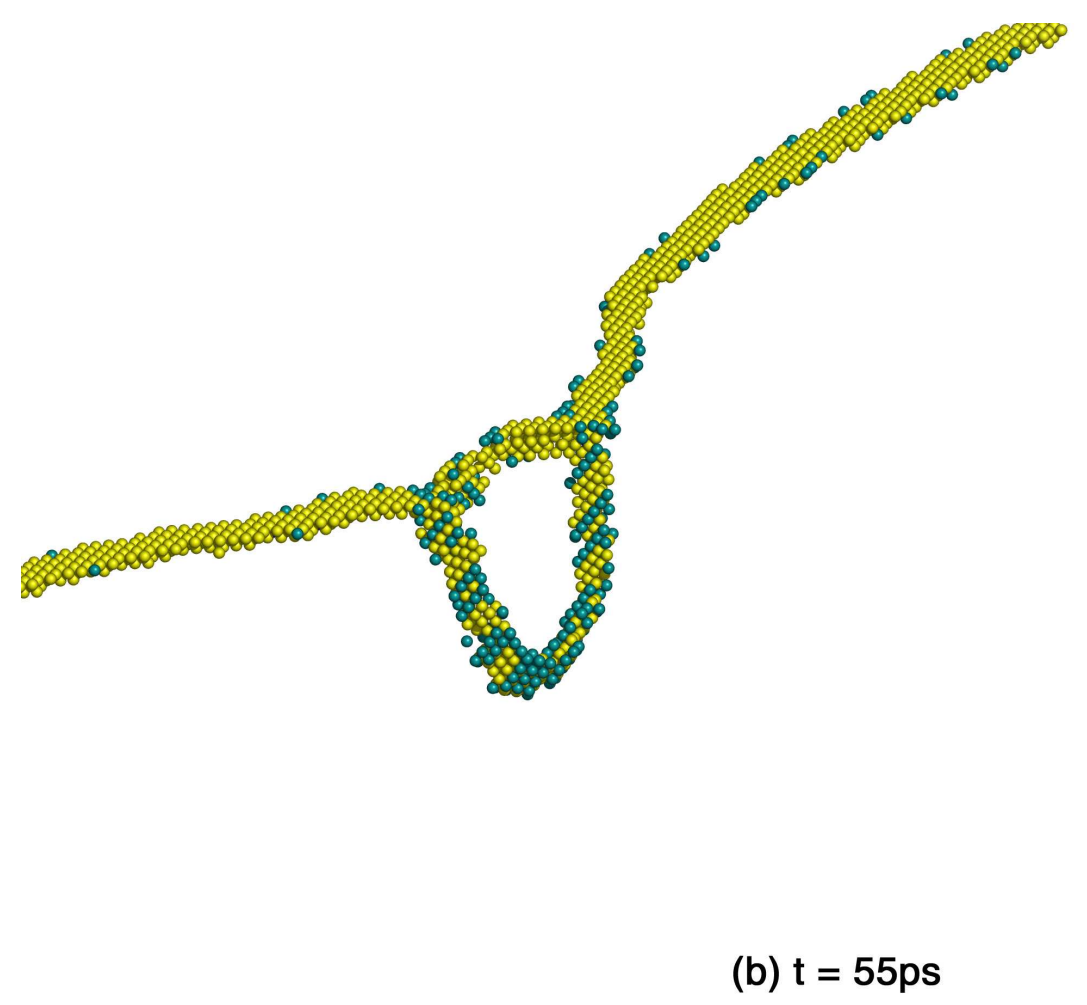

Figure $5 b$

$846 \times 635 \mathrm{~mm}(72 \times 72$ DPI $)$ 
Page 53 of 59

Philosophical Magazine \& Philosophical Magazine Letters

$$
\begin{aligned}
& 1 \\
& 2 \\
& 3 \\
& 4 \\
& 5 \\
& 6 \\
& 7 \\
& 8 \\
& 9 \\
& 10 \\
& 11 \\
& 12 \\
& 13 \\
& 14 \\
& 15 \\
& 16 \\
& 17 \\
& 18 \\
& 19 \\
& 20 \\
& 21 \\
& 22 \\
& 23 \\
& 24 \\
& 2 \\
& 25 \\
& 26 \\
& 27 \\
& 28 \\
& 29 \\
& 30 \\
& 3
\end{aligned}
$$

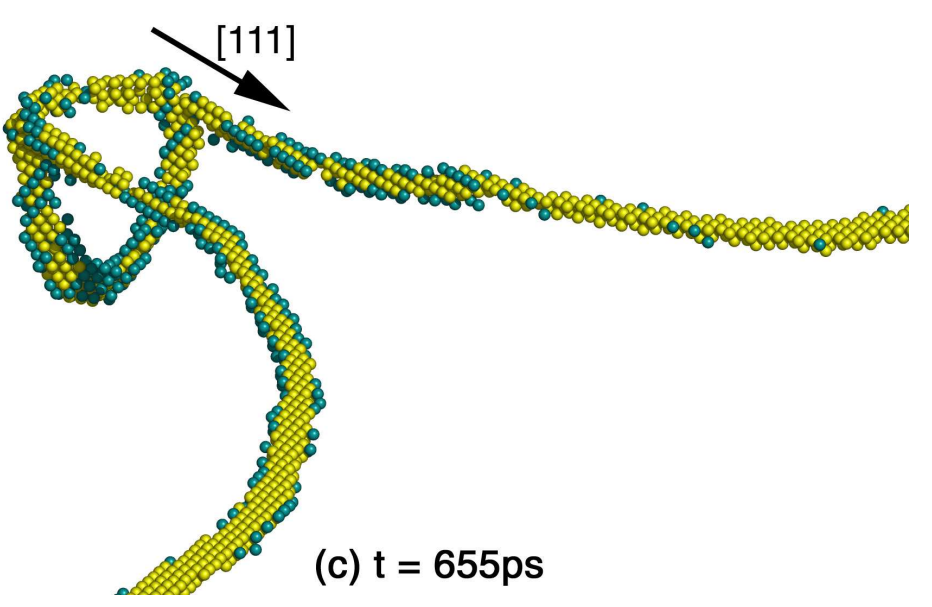

Figure $5 \mathrm{c}$ $846 \times 635 \mathrm{~mm}(72 \times 72$ DPI)

http://mc.manuscriptcentral.com/pm-pml 


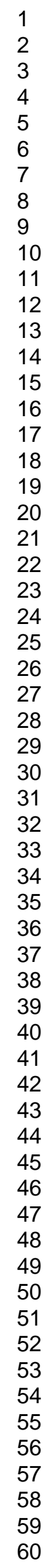

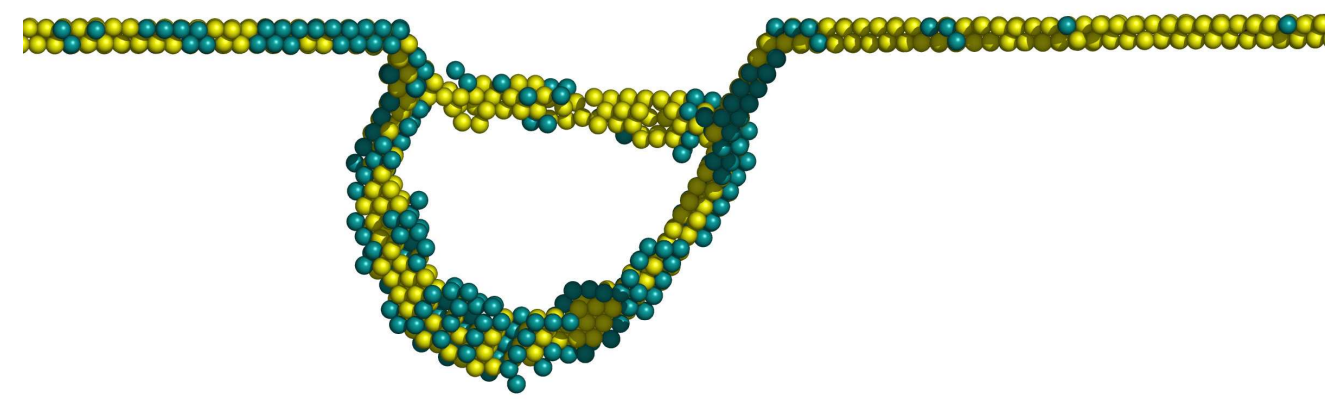

(d) $t=655 p s$

Figure $5 \mathrm{~d}$

$846 \times 635 \mathrm{~mm}(72 \times 72 \mathrm{DPI})$ 


1
2
3
4
5
6
7
8
9
10
11
12
13
14
15
16
17
18
19
20
21
22
23
24
25
26
27
28
29
30
31
32
33
34
35
36
37
38
39
40
41
42
43
40
45
49
50
51
52
53
55
50

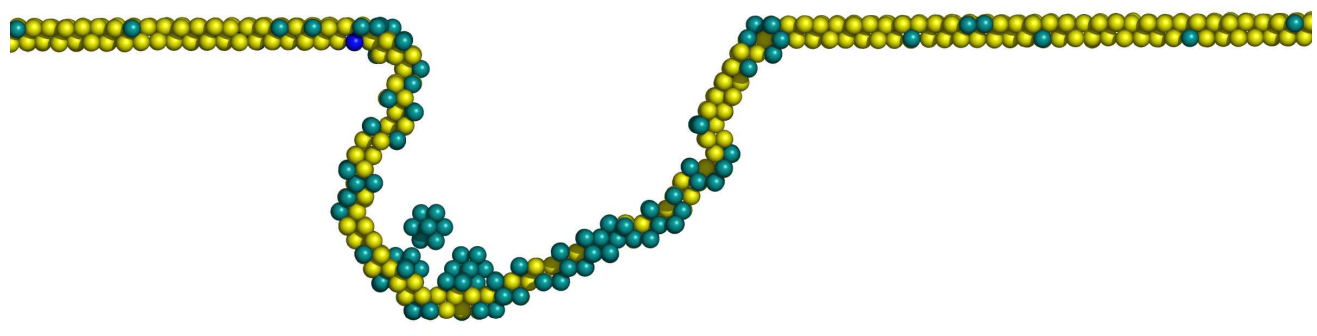

(e) $t=765 p s$

Figure $5 \mathrm{e}$ $846 \times 635 \mathrm{~mm}(72 \times 72 \mathrm{DPI})$ 

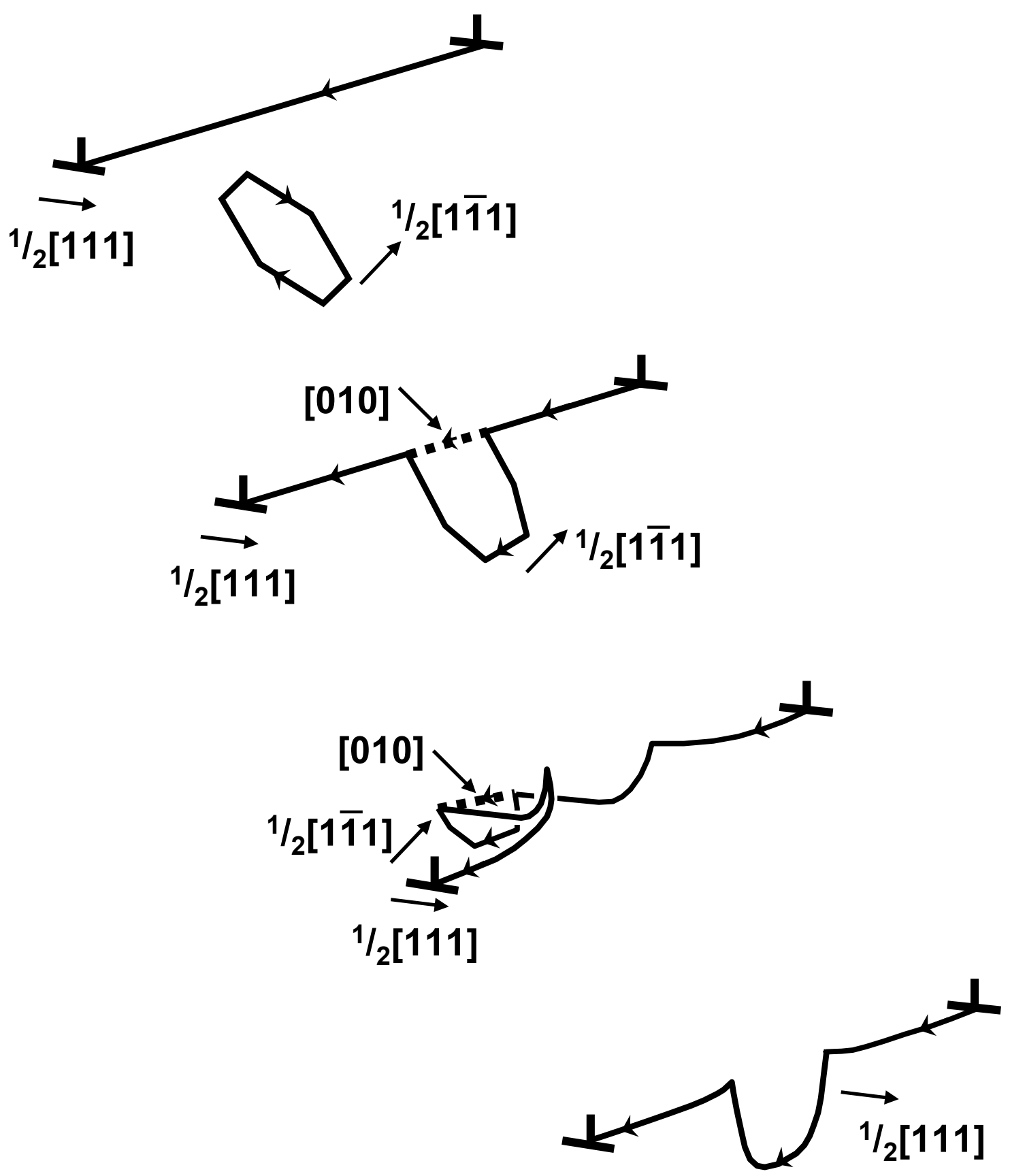
1

2

3

4

5

6

7

8

9

10

11

12

13

14

15

16

17

18

19

20

21

22

23

24

25

26

27

28

29

30

31

32

33

34

35

36

37

38

39

40

41

42

43

44

45

46

47

48

49

50

51

52

53

54

55

56

57

58

59

60

Figure $7 a$

$846 \times 635 \mathrm{~mm}(72 \times 72$ DPI $)$ 


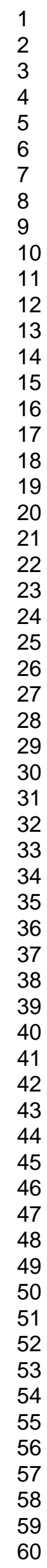

(b) $\mathrm{t}=3.7 \mathrm{~ns}, \tau=240 \mathrm{MPa}$

Figure $7 \mathrm{~b}$

$849 \times 593 \mathrm{~mm}(72 \times 72 \mathrm{DPI})$ 


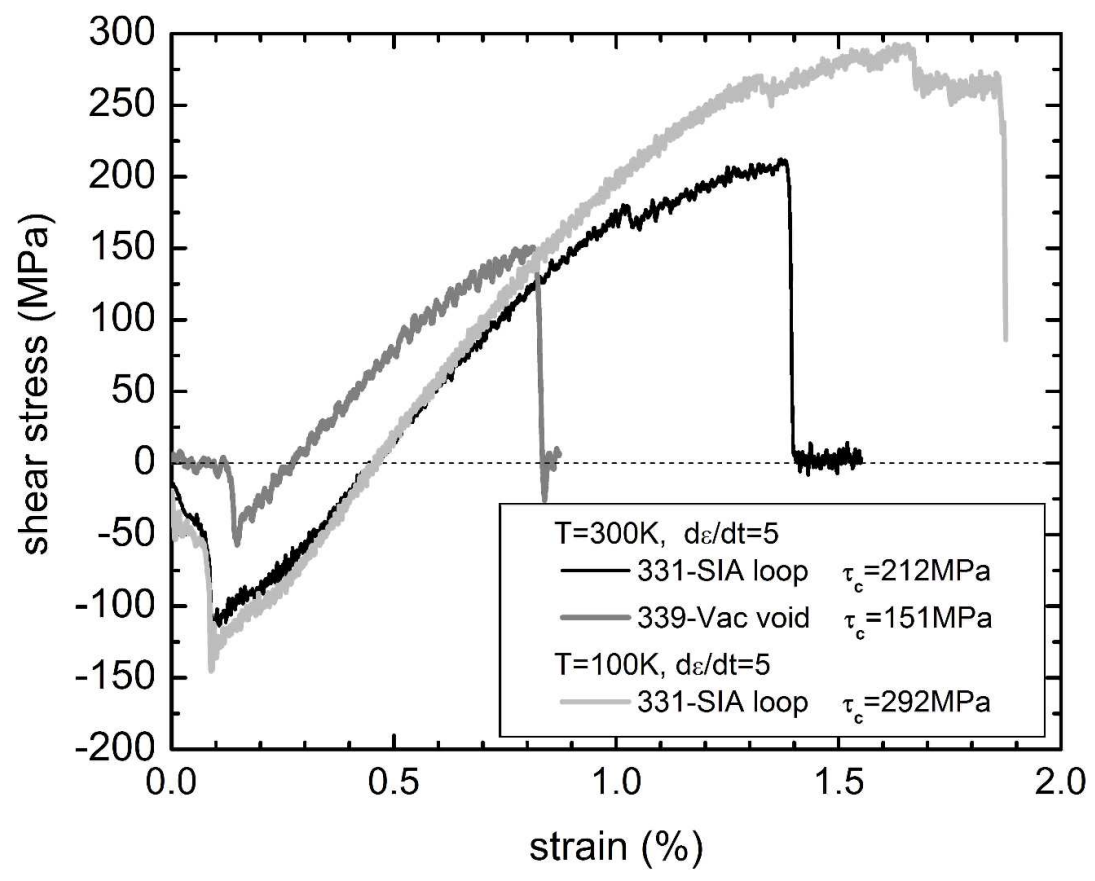

Figure 8

$331 \times 254 \mathrm{~mm}(490 \times 490 \mathrm{DPI})$ 